\title{
Theoretical Studies on the Reactions of Aryl and Hetaryl Thioketones with Nitrilimines
}

\author{
George Baffour Pipim and Ernest Opoku*
}

Center for Molecular Quantum Chemistry Research, Department of Basic and Computational Sciences, Koachie Health Systems, Accra, Ghana

baffourgeorge88@gmail.com, eopoku@koachie.org/ernopoku@gmail.com

\begin{abstract}
Many synthetic routes to constructing biologically-active heterocyclic compounds are made feasible through the $(3+2)$ cycloaddition 32CA reactions. Due to a large number of possible combinations of several heteroatoms from either the three-atom components (TACs) or the ethylene derivatives, the potential of the 32CA reactions in heterocyclic syntheses is versatile. Herein, the 32CA of thiophene-2-carbothialdehyde derivatives and $C, N$-disubstituted nitrilimines have been studied through density functional theory (DFT) calculations at the B3LYP/6-311G(d,p) level of theory. In the present study, one-step $(3+2)$ and two-step $(4+3)$ mechanisms of the addition of the TAC and ethylene derivative have been investigated. In all reactions considered, the one-step $(3+2)$ cycloaddition is preferred over the two-step $(4+3)$ cycloaddition. The TAC chemoselectively adds across the thiocarbonyl group present in the ethylene derivative in a $(3+2)$ fashion to form the corresponding cycloadduct. Analysis of the electrophilic $\left(P_{K}^{+}\right)$and nucleophilic $\left(P_{K}^{-}\right)$Parr functions at the various reaction centers in the ethylene derivative show that the TAC adds across the atomic centers with the largest Mulliken atomic spin densities, which is in total agreement with the experimental observation. The selectivities observed in the title reaction are kinetically controlled.
\end{abstract}

Keywords: Nitrilimines; Thioketones; Cycloadditions; Molecular Mechanism 


\subsection{Introduction}

Cycloaddition reactions present robust synthetic routes for forming a wide range of products with complex stereo- and regio-chemistry. $(3+2)$ and Diels-Alder cycloaddition reactions are common cycloaddition reactions that provide efficient methods for constructing vital heterocyclic and carbocyclic compounds [1-4]. The synthetic applicability of $(3+2)$ cycloaddition (32CA) reactions in modern-day chemistry is overwhelming $[5,6]$. The exact mechanistic peculiarity of a particular 32CA reaction depends critically on a delicate interplay of several factors, primarily the electronic and steric nature of the substituents on the reacting species $[7,8]$.

Recently, massive attention has been shifted to the chemistry of compounds containing thioureas, thioamides, and thioketones. The extremely reactive nature of thioketones makes them essential precursors in the synthesis of heterocyclic compounds. Thioketones serve as efficient ethylene derivatives for constructing five-membered heterocyclic compounds [9] of remarkable versatility in academia and industry. Thioketones are referred to as "superdipolarophiles" due to their unique reactivity towards some types of three-atom components(TAC) [10].

Huisgen and Rapp [11] reported a 32CA reaction between aromatic thioketones and dimethyl acetylenedicarboxylate in chloroform yielding dimethyl 3,3-diphenyl-3H-1,2-dithiole-4,5dicarboxylate and benzothiopyran with the latter taking dominance yield. The benzothiopyran and related systems have critical biological activity. Koga et al. [10] also reported a similar heteroDiels -Alder reaction between aromatic thioketones and benzyne. Similarly, Grzegorz et al. [12] reported chemo- and regio-selective hetero-Diels-Alder reaction between hetaryl thioketone and activated acetylenecarboxylates followed by a 1,3-hydrogen shift to yield thiopyran derivatives with important biological activity.

Aromatic and cycloaliphatic thioketones have gained significant interest due to their extreme reactivity towards a wide variety of TACs [13]. While the one-step mechanism of addition has 
been mostly reported in literature, the reactions of aryl/hetaryl and dihetaryl thioketone with diazoalkanes and thiocarbonyl ylides have been reported to proceed via a diradical two-step mechanism [14-17]. Mloston et al. [18] reported a novel 32CA reaction between enantiopure carbohydrate-derived nitrones and cycloaliphatic thioketones. The reaction was carried out in tetrahydrofuran at room temperature yielding 1,4,2-oxathiazolidines with complete regioselectivity. Mloston et. al.[19] reported a regio-selective 32CA between phenyl (thiophen-2yl) methanethione (1) with in situ generated $N$-aryl-C-trifluoromethyl nitrilimine (2) as shown in scheme 1 . The reaction chemoselectively led to the formation of 2,3-dihydro-1,3,4-thiadiazole derivatives (3). The 1,3,4-thiazolidine unit serves as a core structure in the synthetic construction of various drugs such as antimicrobial, antineoplastic, analgesics, and antitubercular agents [20].

Scheme 1: 32CA between phenyl(thiophen-2-yl)methanethione (1) with in situ generated $N$-aryl$C$-trifluoromethyl nitrilimine (2) [19].
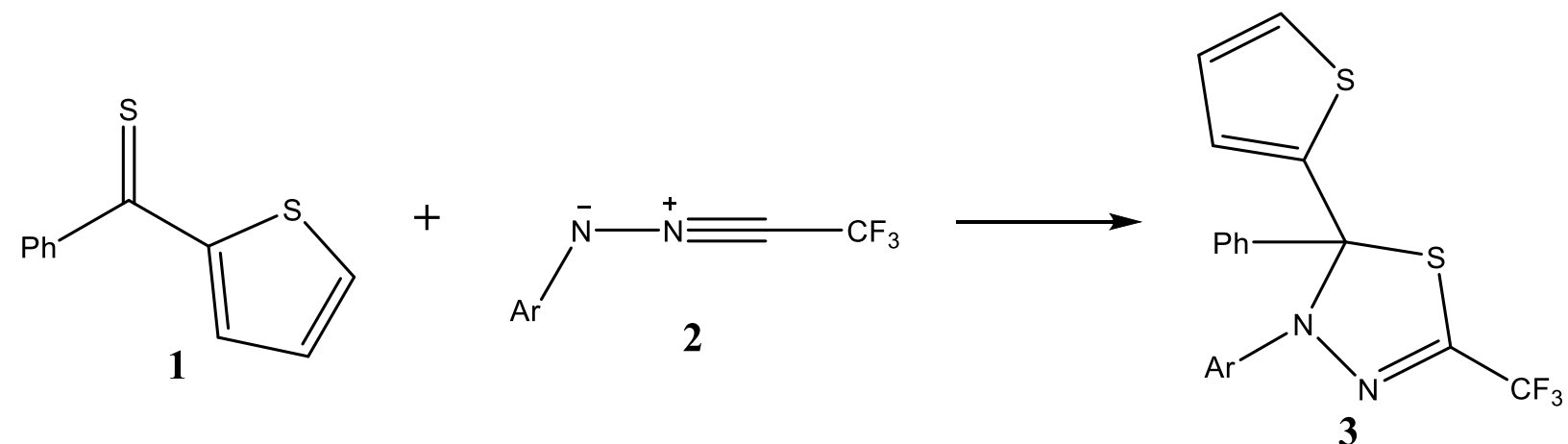

A manifold of theoretical and experimental studies on reactions of TAC and ethylene derivatives have been reported in recent literature. No theoretical study on reactions of aryl hetaryl thioketones and nitrile imines are known to the authors. In this work, we present a systematic theoretical study on the novel reaction between aryl hetaryl thioketones and nitrile imines. The molecular mechanism, substrate reactivity and factors controlling the chemo-, regio-, stereo- and enantioselectivities involved in this reaction are conclusively settled. A wide range of substituents with different electronic and steric influences on both reactants have been studied to provide molecular- 
level insights into how different substituents affect product distribution. These mechanistic concerns are addressed with the aid of proposed reaction schemes 2 and 3. 
Scheme 2: Proposed Scheme of Study for the 32CA of Thioketones (A1) and $C, N$-disubstituted Nitrilimines (A2)

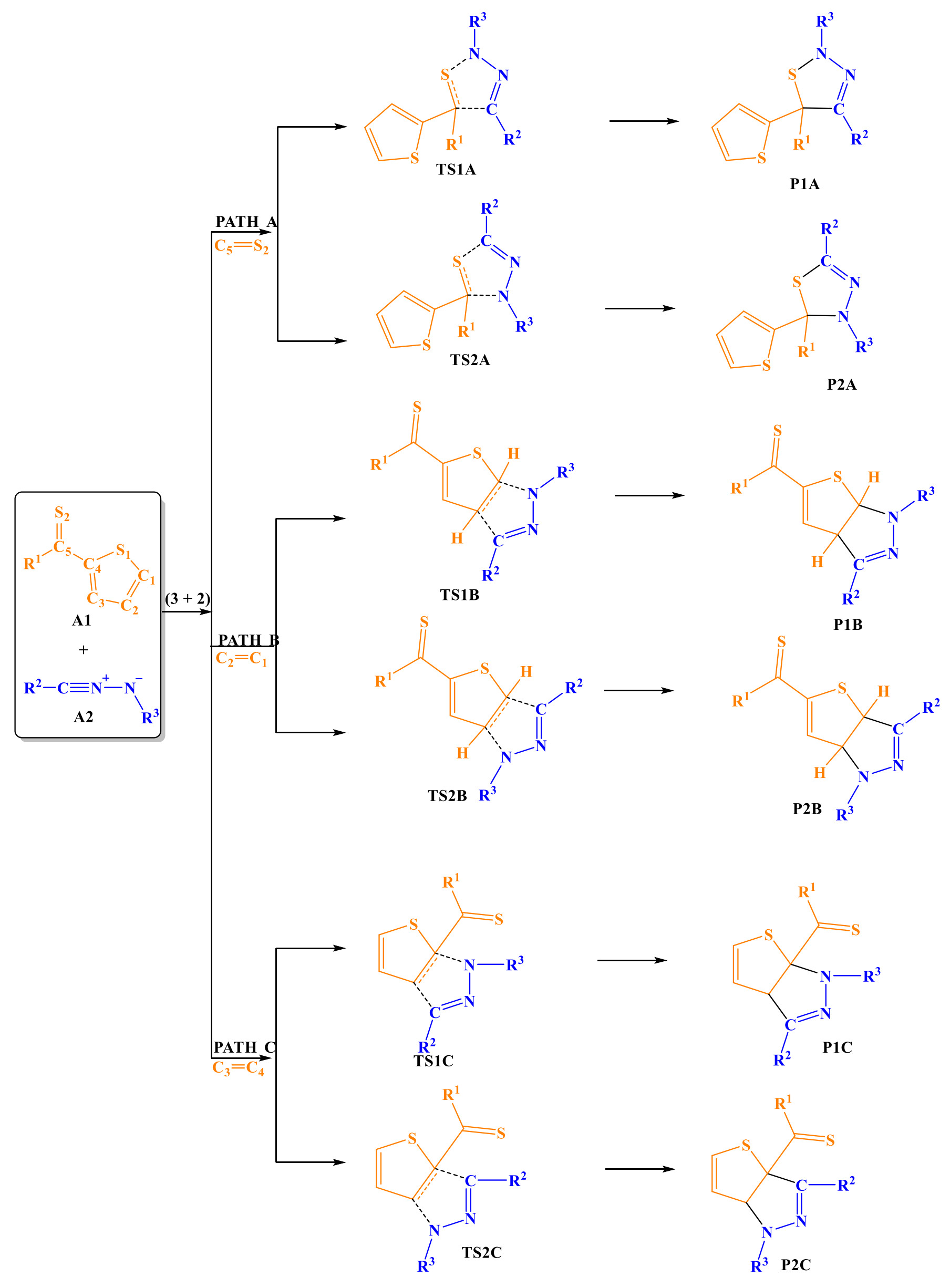


Scheme 3: Proposed Scheme of Study for the $(4+3)$ cycloaddition of Thioketones $($ A1) and $C, N$ disubstituted Nitrilimines (A2)

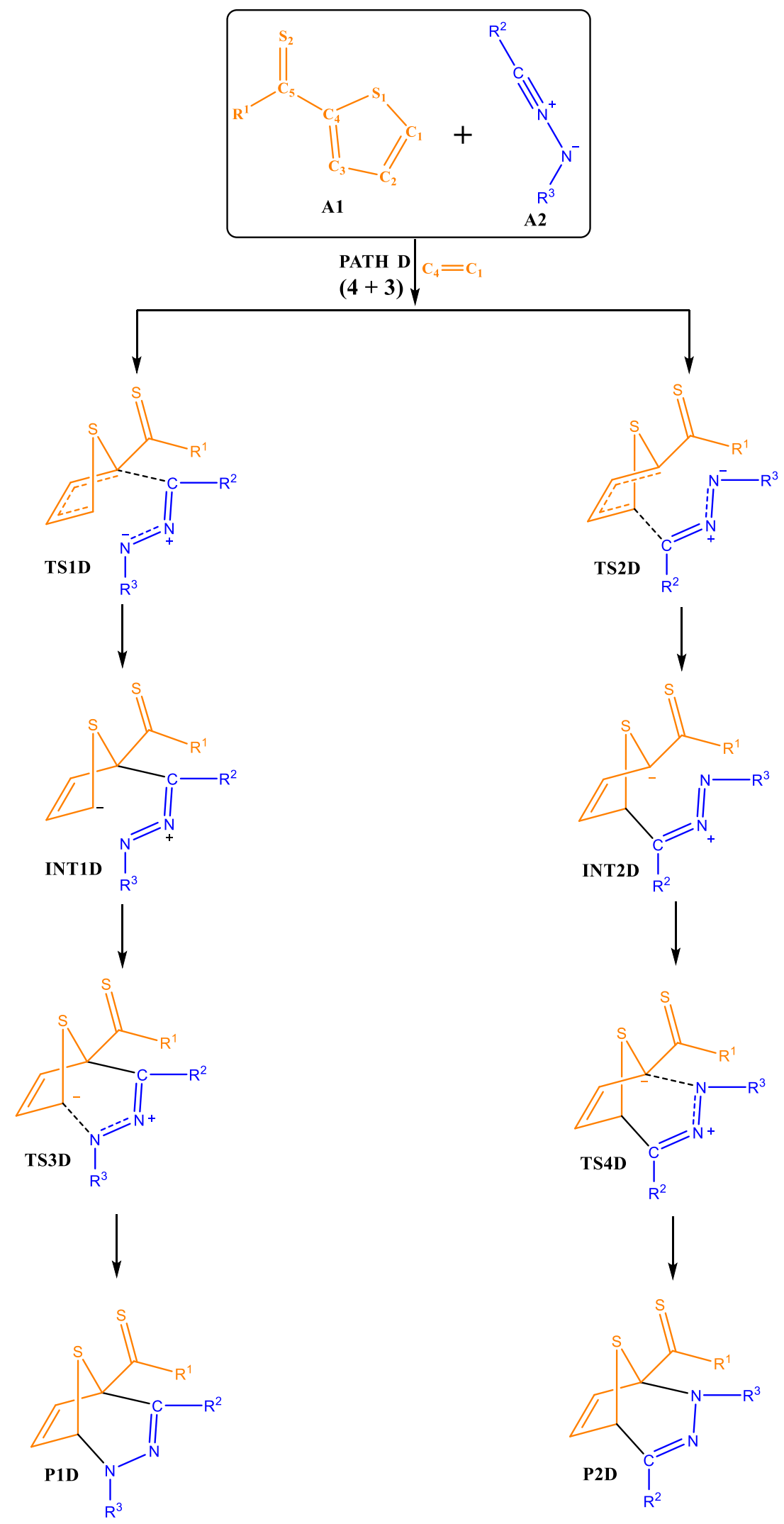




\section{Theory and Methods}

\section{A. DFT Calculations and Geometry Optimizations}

Initial geometries of all the molecules considered in this study were constructed with Avogadro [21] molecular builder and visualizer, and each geometry was minimized interactively using the sybyl force field [22]. Transition state (TS) geomtries were computed by constructing guess input structures. This was achieved by constraining specific internal coordinates of the molecules (bond lengths, bond angles, dihedral angles) while fully optimizing the remaining internal coordinates. This procedure offers a suitable initial TS input geometries which are then submitted for full TS calculations without any geometry or symmetry constraints. The geometry optimization of all minima and maxima structures were achieved through the Berny analytical gradient optimization method developed by Schlegel [23]. Full harmonic vibrational frequency calculations were imposed to substantiate that each TS converged geometry had a Hessian matrix with only a single negative eigenvalue, characterized by an imaginary vibrational frequency along the respective reaction coordinates. The default self-consistency field (SCF) convergence criteria (SCF=Tight) within the Gaussian 16 quantum chemistry program was used [24,25]. Intrinsic reaction coordinate calculations [25-27] were then performed to ensure that each TS smoothly connects the reactants and products along the reaction coordinate [28-30]. We used the CYLview for visualization and illustration of all the optimized structures [31].

All the DFT calculations were executed with the Gaussian 16 [32] computational chemistry software package at the B3LYP/6-311G(d,p) level of theory. The B3LYP is a gradient-corrected functional of Becke, Lee, Yang, and Parr for exchange and correlation. The B3LYP has been found to be an excellent functional for the study of cycloaddition reactions, especially those involving low activation barriers [33]. The B3LYP functional is a Hartree-Fock DFT hybrid functional which has been the bedrock of quantum chemical studies on organic molecules over the years [34]. 
Organic reactions that proceed with low energy barriers [35] are best studied with the B3LYP functional as it averts the challenges of recording near negative activation barriers with, for instance, M06-2X [36] hybrid meta-generalized gradient approximation functional.

\section{B. Reactivity Indices}

The global electrophilicities $(\boldsymbol{\omega})$ and maximum electronic charge $\left(\Delta \mathbf{N}_{\max }\right)$ of the various aryl hetaryl thioketones and $C, N$-disubstituted nitrilimine derivatives were calculated using equations (1) and (2).

$$
\begin{gathered}
\omega=\frac{\mu^{2}}{2 \eta} \\
\Delta N_{\max }=\frac{-\mu}{\eta}
\end{gathered}
$$

The electrophilicity index gives a quantitative measure of the ability of a reaction substrate to accept electrons [37] and it is a function of the electronic chemical potential, $\mu=($ Еномо + $\left.\mathrm{E}_{\mathrm{Lumo}}\right) / 2$ and chemical hardness, $\eta=\left(\mathrm{E}_{\mathrm{Lumo}}-\mathrm{E}_{\text {Hомо }}\right)$ [38]. Therefore, species with large electrophilicity values are more reactive towards nucleophiles in a given set of reagents. These equations are based on the Koopmans theory [39] originally established for calculating ionization energies from closed-shell Hartree-Fock wavefunctions, but have since been adopted as acceptable approximations for computing electronic chemical potential and chemical hardness. The maximum electronic charge transfer $\left(\Delta \mathrm{N}_{\max }\right)$ measures the maximum electronic charge that the electrophile may accept. Thus, species with the largest $\Delta \mathrm{N}_{\max }$ index would be the best electrophile given a series of compounds.

The local electrophilic $\left(P_{K}^{+}\right)$and nucleophilic $\left(P_{K}^{-}\right)$Parr functions were obtained through the analysis of the Mulliken atomic spin densities (ASD) of the radical anion and the radical cation by single-point energy calculations over the optimized neutral geometries using the unrestricted 
UB3LYP formalism for the radical species [40]. The nucleophilicity index of the various reagents were calculated using equation (3). The scale of nucleophilicity is made in referrence to tetracyanoethylene (TCE) [41].

$$
N_{(n u)}=E_{\text {Hомо }(n u)}(e V)-E_{\text {Hомо }(T C E)}(e V)
$$

The global electron density transfer [42] (GEDT) was computed by the sum of the natural atomic charges, obtained by a Natural Population Analysis [43,44] (NPA) of the atoms belonging to each framework at the TSs. The sign indicates the direction of the electron density flux in such a manner that positive values mean a flux from the considered framework to the other one and vice versa.

\section{Rate Constants}

The rate constants of the reaction at a specific temperature $[k(T)]$ for the reaction of phenyl(thiophen-2-yl)methanethione and $N$-phenyl- $C$-trifluoromethyl nitrilimine calculated using equation (4) [45].

$$
k(T)=\frac{K_{B} T}{h c^{\circ}} e^{-\Delta^{\ddagger} G^{\circ} / R T}
$$

where $\mathrm{k}_{\mathrm{B}}=1.380662 \times 10^{-23} \mathrm{~J} / \mathrm{K}$ is the Boltzmann's constant, $\mathrm{T}=298.15 \mathrm{~K}$ is the reaction temperature, $h=6.62617 \times 10^{-34} \mathrm{~J} . \mathrm{s}$ is the Planck's constant, $\mathrm{R}=1.987 \mathrm{cal} / \mathrm{mol} . \mathrm{K}$ is the molar gas constant, $\Delta^{\ddagger} G^{\circ}$ is the Gibbs free energy of activation and $\mathrm{R}$ is the molar gas constant, and $c^{\circ}$ is the concentration of the reacting species which is taken as 1 . 


\subsection{Results and Discussion}

The multiple reaction centers present in the thiophene-2-carbothialdehyde derivatives (ethylene derivative) avails different modes of addition to the $C, N$-disubstituted nitrilimines (TAC). Based on the ethylene derivative's geometric orientation towards the TAC, a $(3+2)$ or $(4+3)$ cycloaddition may result. In this present study, three characteristics $(3+2)$ cycloaddition reaction routes have been investigated alongside a distinctive $(4+3)$ cycloaddition reaction channel.

From scheme 2 , a $(3+2)$ cycloaddition originates from the addition of the TAC across the thiocarbonyl group of the ethylene derivative (A1) labeled as Path A. Two different reaction channels stem from Path A yielding the regioisomeric products P1A and P2A. The structural formula P1A arises from the preferential attachment of the nitrilimine carbon (A2) to the thiocarbonyl group's carbon atom to yield the 1,2,3-thiadiazole ring. P2A arises from the selective attachment of the nitrilimine carbon (A2) to the thiocarbonyl group's sulfur atom to generate a 1,3,4-thiadiazole ring.

The addition of the TAC across the $\mathrm{C}_{1}$ and $\mathrm{C}_{2}$ bond (the less-hindered side of the thiophene ring) yields a different reaction route labeled Path B in scheme 2, which encompasses two different reaction channels. P1B and $\mathbf{P 2 B}$ are regioisomers arising from Path B, as shown in scheme 2. An alternative mode of 32CA emanates from the addition of the TAC across the $\mathrm{C}_{3}$ and $\mathrm{C}_{4}$ bond (the hindered side of the thiophene ring) of A1, yielding the reaction route labeled Path C. The structural formulas P1C and $\mathbf{P 2 C}$ are regioisomers arising from Path C.

In scheme 3, we propose a two-step (4 + 3) cycloaddition reaction between $\mathbf{A 1}$ and $\mathbf{A 2}$ to furnish two regio-isomers P1D and P2D. A thorough search for a possible one-step $(4+3)$ cycloaddition reaction route between $\mathbf{A} \mathbf{1}$ and $\mathbf{A} 2$ proved futile. Hence, a one-step (4 + 3) pathway has been ruled out from our present discussion. 


\subsection{Analysis of the Parent Reaction of Phenyl(thiophen-2-yl)methanethione (A1) with $N$ - phenyl- $C$-trifluoromethyl Nitrilimine (A2)}

The mechanism and selectivities involved in the reaction of phenyl(thiophen-2-yl)methanethione $\left(\mathbf{A 1}, \mathrm{R}^{1}=\mathrm{Ph}\right)$ and $N$-phenyl- $C$-trifluoromethyl nitrilimine $\left(\mathbf{A 2}, \mathrm{R}^{2}=\mathrm{CF}_{3}, \mathrm{R}^{3}=\mathrm{Ph}\right)$ have been investigated and the results discussed in this section. The energy profile for the $(3+2)$ cycloaddition reaction of phenyl(thiophen-2-yl)methanethione $\left(\mathbf{A 1}, \mathrm{R}^{1}=\mathrm{Ph}\right)$ with $N$-phenyl-Ctrifluoromethyl nitrilimine $\left(\mathbf{A 2}, \mathrm{R}^{2}=\mathrm{CF}_{3}, \mathrm{R}^{3}=\mathrm{Ph}\right)$ is shown in figure 1. Figure 2 shows the energy profile for the $(4+3)$ cycloaddition reaction of phenyl(thiophen-2-yl) methanethione $\left(\mathbf{A 1}, \mathrm{R}^{1}=\right.$ $\mathrm{Ph})$ with $N$-phenyl- $C$-trifluoromethyl nitrilimine $\left(\mathbf{A 2}, \mathrm{R}^{2}=\mathrm{CF}_{3}, \mathrm{R}^{3}=\mathrm{Ph}\right)$. Figure 3 is a graphical representation of the stationary point structures with geometrical parameters for the two-step $(4+$ 3) cycloaddition reaction between $N$-phenyl- $C$-trifluoromethyl nitrilimine $\left(\mathbf{A 2}, \mathrm{R}^{2}=\mathrm{CF}_{3}, \mathrm{R}^{3}=\mathrm{Ph}\right)$ and phenyl(thiophen-2-yl)methanethione $\left(\mathbf{A 1}, \mathrm{R}^{1}=\mathrm{Ph}\right)$. The rate constants for the formation of the various isomeric cycloadducts and intermediates considered in scheme 2 for the reaction of phenyl(thiophen-2-yl)methanethione $\left(\mathbf{A 1}, \mathrm{R}^{1}=\mathrm{Ph}\right)$ and $N$-phenyl- $C$-trifluoromethyl nitrilimine $\left(\mathbf{A 2}, \mathrm{R}^{2}=\mathrm{CF}_{3}, \mathrm{R}^{3}=\mathrm{Ph}\right)$ have been calculated and results shown in table 1.

In the present study, one-step and two-step mechanisms of addition have been investigated for both $(3+2)$ and $(4+3)$ cycloaddition reactions of phenyl(thiophen-2-yl) methanethione (A1) with $N$-phenyl- $C$-trifluoromethyl nitrilimine $\left(\mathbf{A 2}, \mathrm{R}^{2}=\mathrm{CF}_{3}, \mathrm{R}^{3}=\mathrm{Ph}\right)$. An asynchronous one-step mechanism of addition is observed for the $(3+2)$ addition of the TAC across the ethylene derivative. No stationary point structures were obtained for the two-step $(3+2)$ mechanism of the addition of the TAC across the ethylene derivative. The geometries of the TS structures obtained for the one-step $(4+3)$ cycloaddition of the TAC across the ethylene derivative suggested that the $(4+3)$ addition proceeds via a two-step mechanism with an initial carbon-carbon bond formation 
between $\mathbf{A 1}$ and $\mathbf{A 2}$. From the energetics displayed in figures 1 and 2, the reaction between phenyl(thiophen-2-yl)methanethione $\left(\mathbf{A 1}, \mathrm{R}^{1}=\mathrm{Ph}\right)$ and $N$-phenyl- $C$-trifluoromethyl nitrilimine $\left(\mathbf{A 2}, \mathrm{R}^{2}=\mathrm{CF}_{3}, \mathrm{R}^{3}=\mathrm{Ph}\right)$ preferentially goes through a $(3+2)$ addition rather than the $(4+3)$ addition. The TAC chemoselectively adds across the thiocarbonyl group of the ethylene derivative (path A), which is consistent with the experimental observation. The most kinetically favored reaction route occurring along path $\mathrm{A}$ is the formation of $\mathbf{P 2 A}$ with a reaction energy of -29.7 $\mathrm{kcal} / \mathrm{mol}$ through TS2A with an activation energy of $3.5 \mathrm{kcal} / \mathrm{mol}$ and has the highest calculated rate constant of $1.7 \times 10^{10} \mathrm{~s}^{-1}$. The regioisomer P1A is the closest competing pathway that proceeds through TS1A with an activation energy of $10.5 \mathrm{kcal} / \mathrm{mol}$ and a rate constant of $1.2 \times 10^{5} \mathrm{~s}^{-1}$. The rate of formation of P2A is approximately 141666 times faster than the formation of P1A through TS1A. The addition of the TAC across the $\mathrm{C}_{1}$ and $\mathrm{C}_{2}$ (less-hindered of the thiophene ring) endocyclic olefinic bond of the ethylene derivative (path B) is kinetically favored over the addition across the $\mathrm{C}_{3}$ and $\mathrm{C}_{4}$ (hindered of the thiophene ring) olefinic bond of the ethylene derivative (path C), as evident from the energies shown in figure 1. The reaction route that proceeds to afford $\mathbf{P} 2 \mathbf{B}$ through T2B is the most favored reaction channel occurring along path B and proceeds with a rate constant of $5.4 \times 10^{4} \mathrm{~s}^{-1}$. The activation energy of T2B is $11.0 \mathrm{kcal} / \mathrm{mol}$, which is $6.3 \mathrm{kcal} / \mathrm{mol}$ lower than the activation energy for the formation of P1B (regioisomer of P2B) through TS1B. The formation of P1C through transition state TS1C is kinetically favored over its regioisomeric cycloadduct P2C.

From figure 2, the formation of INT1D through TS1D proceeds with an activation barrier of 22.8 $\mathrm{kcal} / \mathrm{mol}$. INT1D can undergo cyclization through TS3D with an activation energy of $9.3 \mathrm{kcal} / \mathrm{mol}$ to generate cycloadduct P1D. The formed intermediate INT1D is thermodynamically unstable and can decompose to generate $\mathbf{A 1}\left(\mathrm{R}^{1}=\mathrm{Ph}\right)$ and $\left(\mathbf{A 2}, \mathrm{R}^{2}=\mathrm{CF}_{3}, \mathrm{R}^{3}=\mathrm{Ph}\right)$ by clearing an activation 
barrier of $8.9 \mathrm{kcal} / \mathrm{mol}$, which is kinetically favored over the cyclization step through TS3D. Evident from figure 2, $\mathbf{A 1}\left(\mathrm{R}^{1}=\mathrm{Ph}\right)$ and $\left(\mathbf{A 2}, \mathrm{R}^{2}=\mathrm{CF}_{3}, \mathrm{R}^{3}=\mathrm{Ph}\right)$ can also react through transition state TS2D with an activation energy of $12.0 \mathrm{kcal} / \mathrm{mol}$ to afford INT2D, which undergoes subsequent cyclization through transition state TS4D with an activation energy of $15.8 \mathrm{kcal} / \mathrm{mol}$ to furnish the cycloadduct P2D with reaction energy of $-5.5 \mathrm{kcal} / \mathrm{mol}$. The formation of INT2A is kinetically and thermodynamically favored over the construction of INT1A.

The polar character of the competitive 32CA reactions was analyzed by calculating the GEDT at the two favorable transition states (TS1A, TS2A) associated with the addition of the TAC across the thiocarbonyl group present in A1. Reactions with GEDT values of 0.0 e correspond to nonpolar processes, while values higher than 0.2 e correspond to polar processes $[42,46]$. The $32 \mathrm{CA}$ reaction of $\left(\mathbf{A 1}, \mathrm{R}^{1}=\mathrm{Ph}\right)$ and $\left(\mathbf{A 2}, \mathrm{R}^{2}=\mathrm{CF}_{3}, \mathrm{R}^{3}=\mathrm{Ph}\right)$ through $\mathbf{T S 1 A}$ proceeds via a reverse electron density (REDF) [47,48] whereas the reaction through TS2A proceeds via a froward electron density flux (FEDF) $[47,48]$. The GEDT, which fluxes from $\left(\mathbf{A 1}, \mathbf{R}^{1}=\mathrm{Ph}\right)$ to $\left(\mathbf{A 2}, \mathbf{R}^{2}=\right.$ $\left.\mathrm{CF}_{3}, \mathrm{R}^{3}=\mathrm{Ph}\right)$ is $0.11 \mathrm{e}$ at $\mathbf{T S 1 A}$ and the GEDT which fluxes from $\left(\mathbf{A 2}, \mathrm{R}^{2}=\mathrm{CF}_{3}, \mathrm{R}^{3}=\mathrm{Ph}\right)$ to $(\mathbf{A 1}$, $\left.\mathrm{R}^{1}=\mathrm{Ph}\right)$ is $0.12 \mathrm{e}$ at TS2A. The GEDT value indicates a low polar character in the 32CA reaction involving the addition of the TAC across A1. 


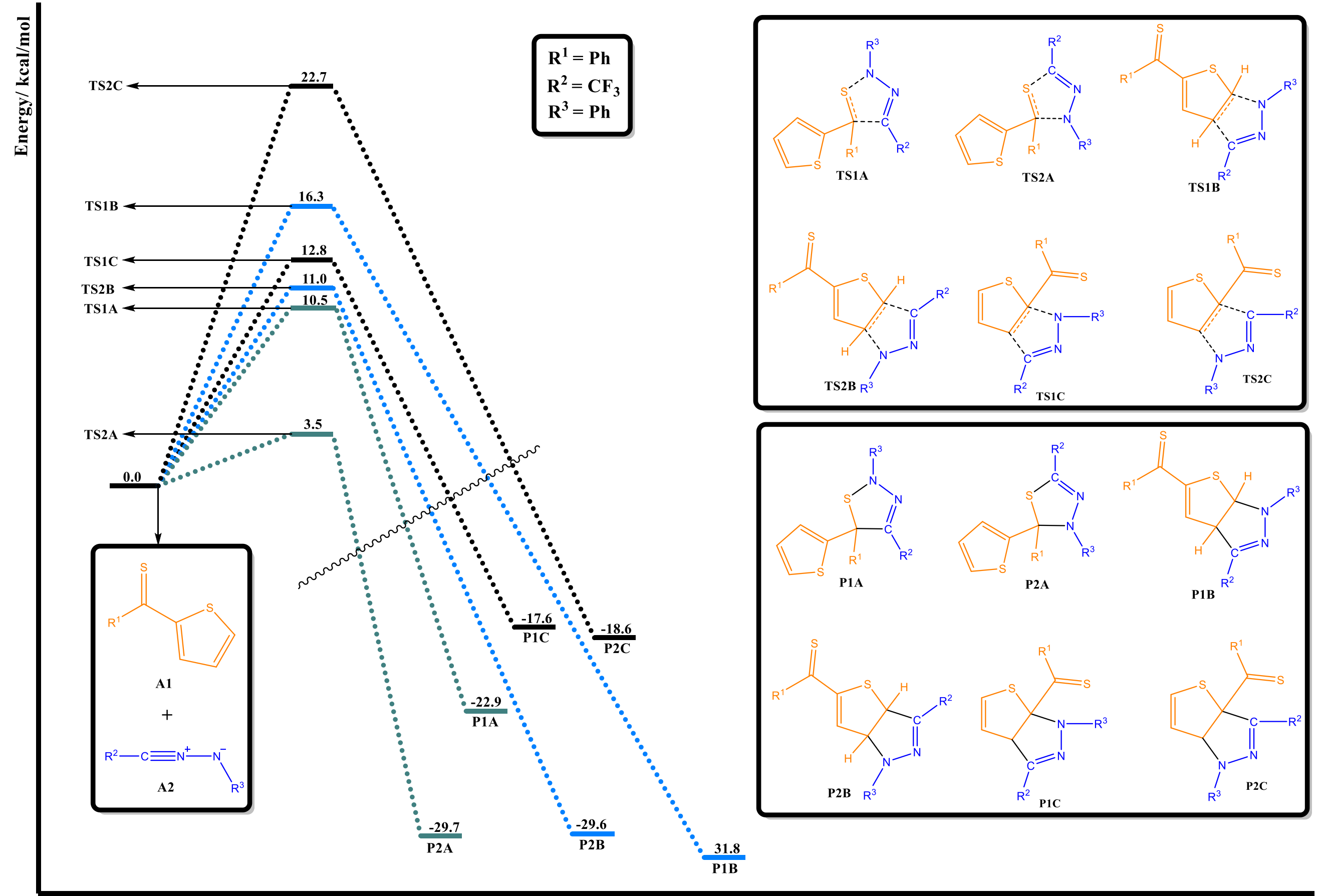

Reaction Coordinate

Figure 1: Energy profile for the 32CA reaction of phenyl(thiophen-2-yl)methanethione $\left(\mathbf{A} 1, \mathrm{R}^{1}=\mathrm{Ph}\right)$ with $N$-phenyl- $C$-trifluoromethyl nitrilimine $\left(\mathrm{A} 2, \mathrm{R}^{2}=\mathrm{CF}_{3}, \mathrm{R}^{3}=\mathrm{Ph}\right)$ in the gas phase at the B3LYP/6-311G $(\mathrm{d}, \mathrm{p})$, level of theory. 


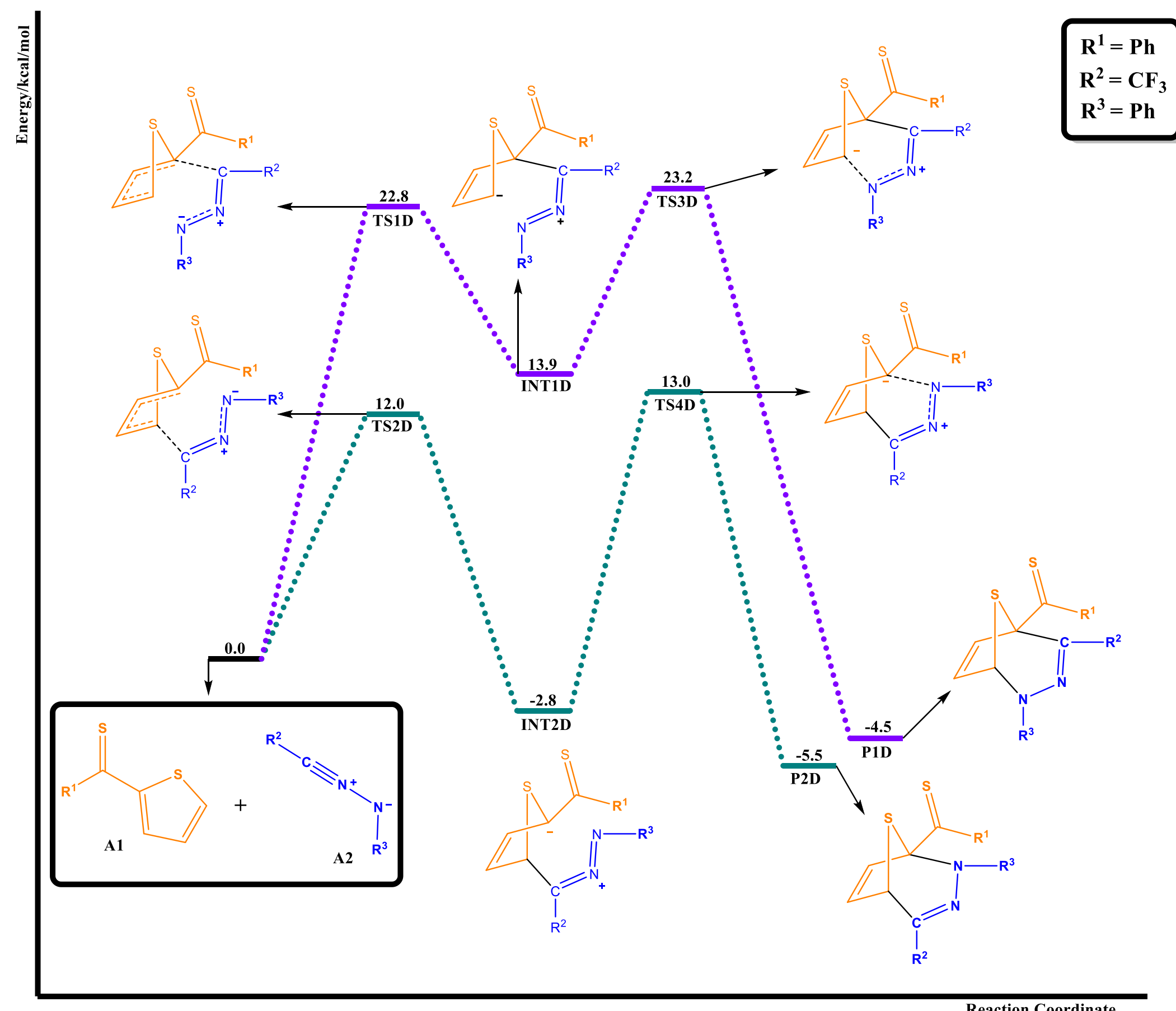

Figure 2: Energy profile for the $(4+3)$ cycloaddition reaction of phenyl(thiophen-2-yl) methanethione $\left(\mathbf{A 1}, \mathrm{R}^{1}=\mathrm{Ph}\right)$ with $N$-phenyl$C$-trifluoromethyl nitrilimine $\left(\mathbf{A 2}, \mathrm{R}^{2}=\mathrm{CF}_{3}, \mathrm{R}^{3}=\mathrm{Ph}\right)$ in the gas phase at the B3LYP/6-311G $(\mathrm{d}, \mathrm{p})$, level of theory. 

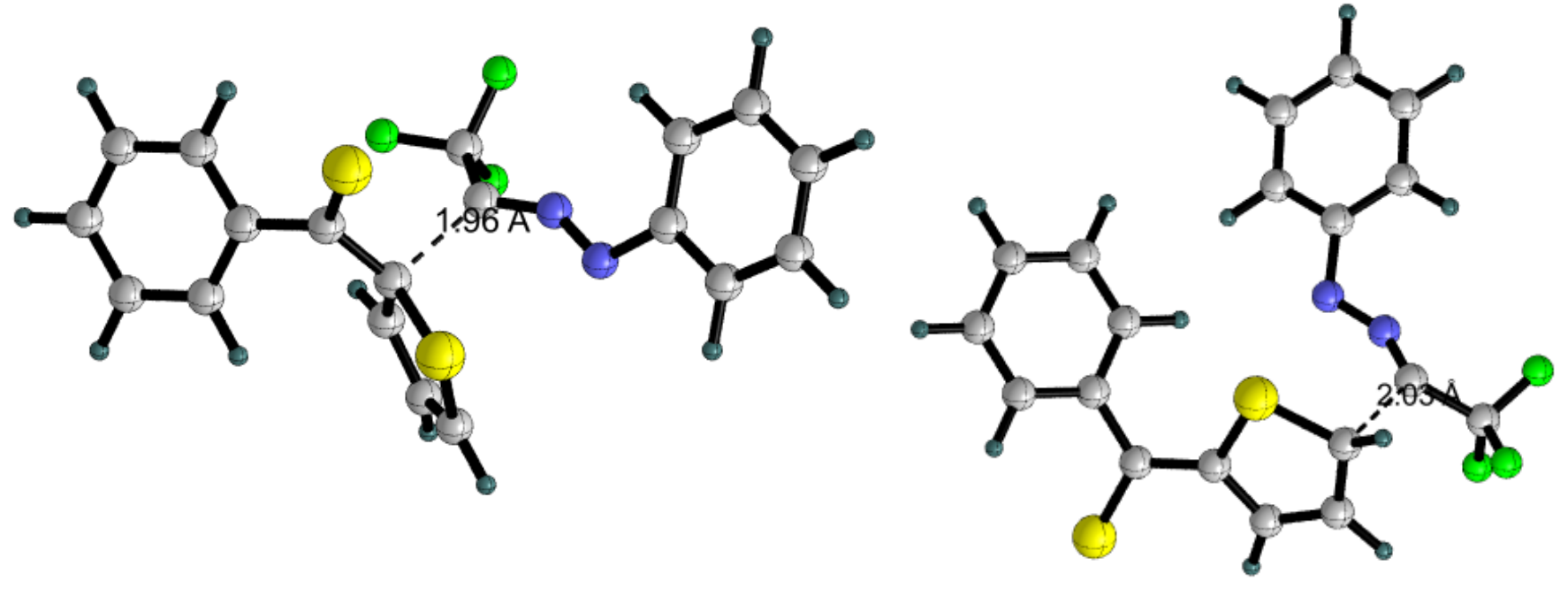

TS1D

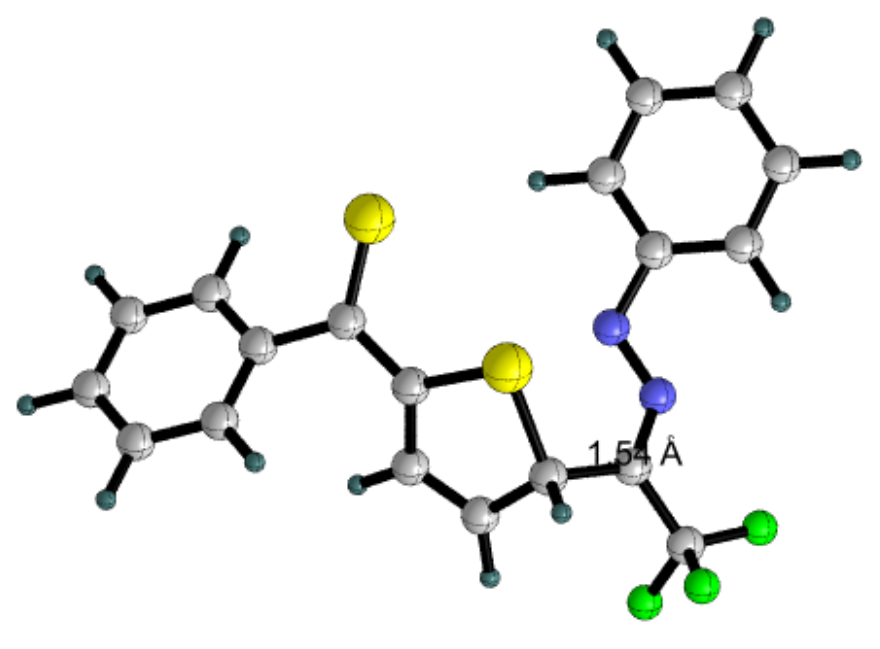

INT2D

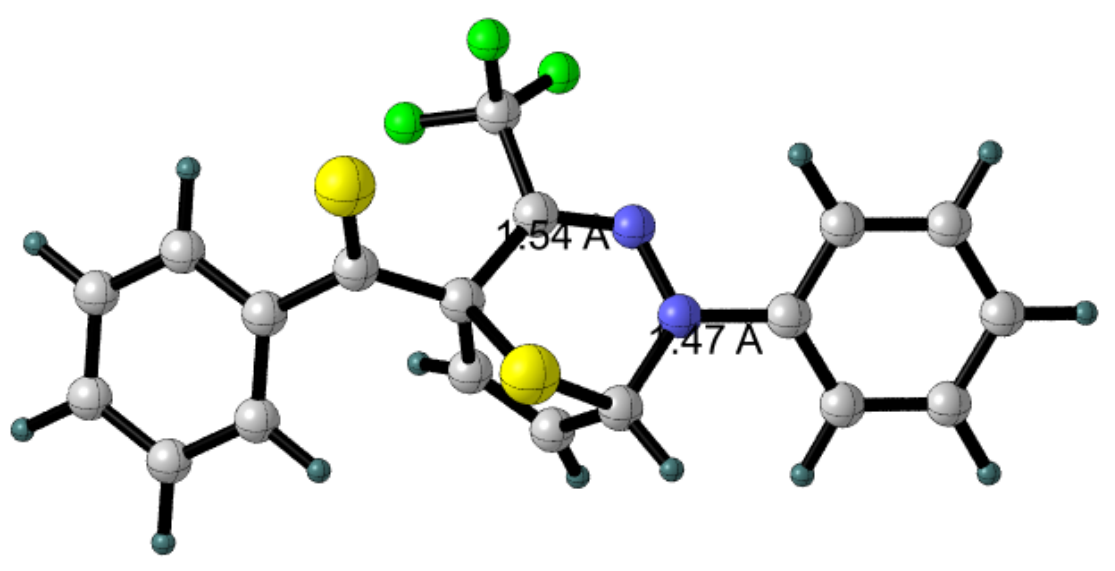

P1D

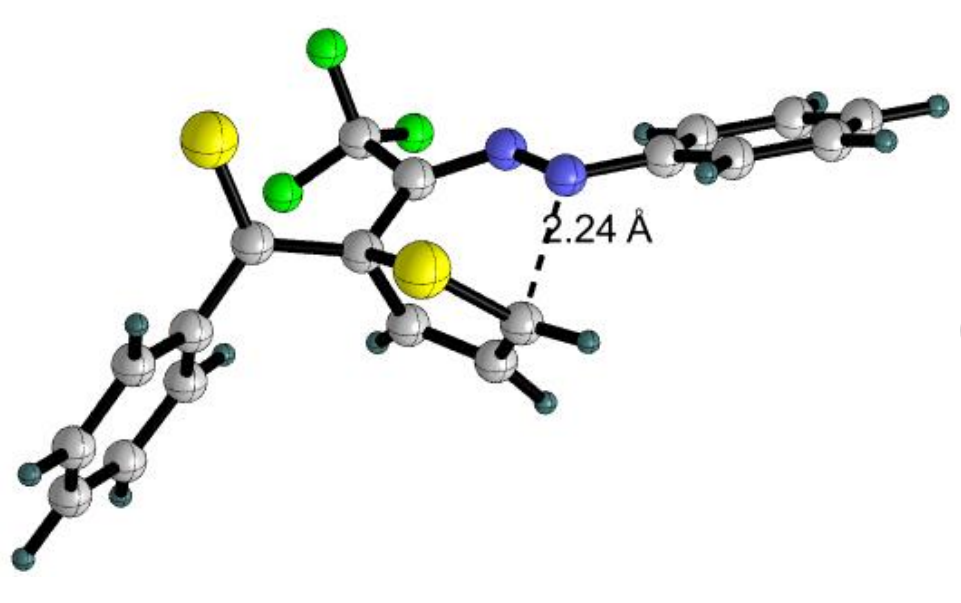

TS3D

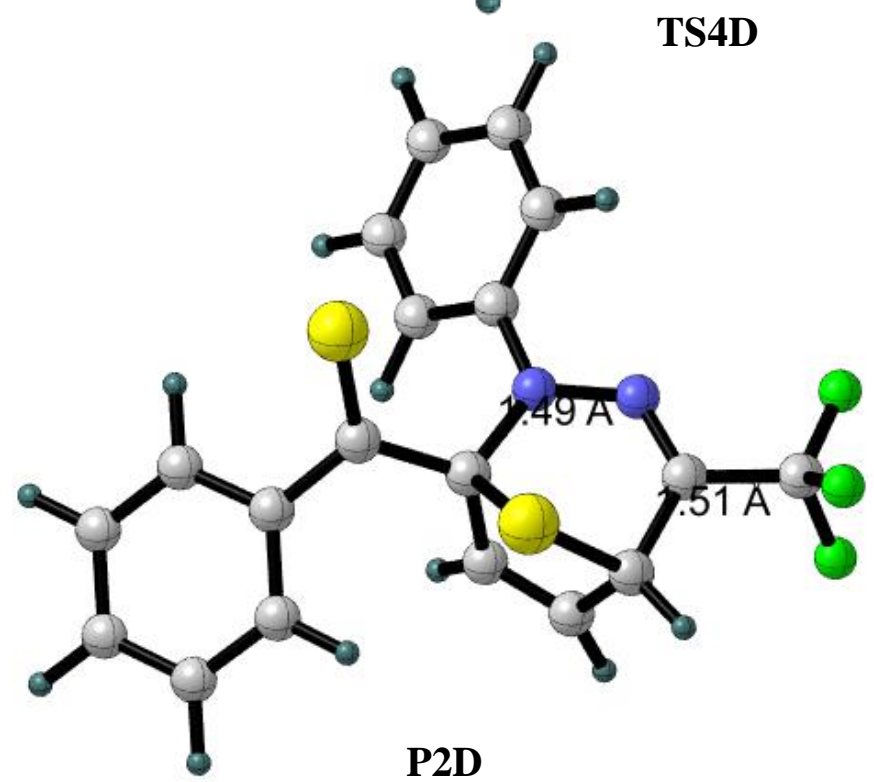

P2D

Figure 3: Graphical representation of optimized stationary point structures for the $(4+3)$ cycloaddition reaction of phenyl(thiophen-2-yl) methanethione $\left(\mathbf{A 1}, \mathrm{R}^{1}=\mathrm{Ph}\right)$ with $N$-phenyl-C-trifluoromethyl nitrilimine $\left(\mathbf{A 2}, \mathrm{R}^{2}=\mathrm{CF}_{3}, \mathrm{R}^{3}=\mathrm{Ph}\right)$ in the gas phase at the B3LYP/6-311G $(\mathrm{d}, \mathrm{p})$, level of theory. 
Table 1: Rate constants $\left(\right.$ in $\left.\mathrm{s}^{-1}\right)$ for the $(3+2)$ and $(4+3)$ cycloaddition reactions of phenyl(thiophen-2yl)methanethione (A1, $\left.\mathrm{R}^{1}=\mathrm{Ph}\right)$ and $N$-phenyl- $C$-trifluoromethyl nitrilimine $\left(\mathbf{A} 2, \mathrm{R}^{2}=\mathrm{CF}_{3}, \mathrm{R}^{3}=\mathrm{Ph}\right)$.

\begin{tabular}{cc}
\hline Product/Intermediate & Rate constants[k(T)] \\
\hline P1A & $1.2 \times 10^{5}$ \\
P2A & $1.7 \times 10^{10}$ \\
P1B & $0.7 \times 10^{1}$ \\
P2B & $5.4 \times 10^{4}$ \\
P1C & $2.6 \times 10^{3}$ \\
P2C & $1.4 \times 10^{-4}$ \\
INT1D & $1.2 \times 10^{-2}$ \\
INT2D & $9.9 \times 10^{3}$ \\
P1D & $9.5 \times 10^{5}$ \\
P2D & $1.6 \times 10^{1}$ \\
\hline
\end{tabular}

\subsection{Effects of Substituents on the Reaction of Phenyl(thiophen-2-yl)methanethione (A1) with $N$-methyl- $C$-substituted Nitrilimine}

The mechanistic effects of substituents with different electronic nature on the TAC in the title reaction have been investigated and the results discussed in this section. Table 2 shows the results for the $(3+2)$ cycloaddition reaction of phenyl(thiophen-2-yl)methanethione $\left(\mathbf{A 1}, \mathrm{R}^{1}=\mathrm{Ph}\right)$ with nitrilimine derivatives (A2). The $(4+3)$ cycloaddition between $\mathbf{A 1}\left(\mathrm{R}^{1}=\mathrm{Ph}\right)$ and nitrilimine derivatives (A2) have also been examined and the results displayed in table 3. The energy profile for the $(3+2)$ cycloaddition reaction of phenyl(thiophen-2-yl)methanethione $\left(\mathbf{A 1}, \mathrm{R}^{1}=\mathrm{Ph}\right)$ with $N$-methyl- $C$-trifluoromethyl nitrilimine $\left(\mathbf{A} 2, \mathrm{R}^{2}=\mathrm{CF}_{3}, \mathrm{R}^{3}=\mathrm{CH}_{3}\right)$ is shown in figure 4. Figure 5 shows the energy profile for the $(4+3)$ cycloaddition reaction of phenyl(thiophen-2-yl) methanethione (A1, $\left.\mathrm{R}^{1}=\mathrm{Ph}\right)$ with 2,2,2-trifluoro-1-(methyldiazen-1-ium-1-ylidene)ethan-1-ide $\left(\mathbf{A} 2, \mathrm{R}^{2}=\mathrm{CF}_{3}, \mathrm{R}^{3}=\mathrm{CH}_{3}\right)$. 
From the energetics displayed in figures 4 and 5, the $(3+2)$ cycloaddition reaction between $\mathbf{A 1}$ $\left(\mathrm{R}^{1}=\mathrm{Ph}\right)$ and $\left(\mathbf{A 2}, \mathrm{R}^{2}=\mathrm{CF}_{3}, \mathrm{R}^{3}=\mathrm{CH}_{3}\right)$ is kinetically favored the $(4+3)$ cycloaddition reaction. Analysis of the energetics displayed in figure 4 shows the TAC $\left(\mathbf{A 2}, \mathrm{R}^{2}=\mathrm{CF}_{3}, \mathrm{R}^{3}=\mathrm{CH}_{3}\right)$ chemoselectively adds across the thiocarbonyl group (path A) of the ethylene derivative (A1, $\mathbf{R}^{1}$ $=\mathrm{Ph})$, which is consistent with the preferred reaction path established in section 3.1. Similar to the parent reaction, the most favorable reaction channel is the formation of P2A through cyclic transition state TS2A with an activation energy of $4.0 \mathrm{kcal} / \mathrm{mol}$, whereas the formation of its regioisomer P1A proceeds through TS1A with an energy barrier of $11.1 \mathrm{kcal} / \mathrm{mol}$. The formation of P2A is highly exergonic with a reaction energy of $-36.4 \mathrm{kcal} / \mathrm{mol}$. The least kinetically favored reaction path occurring via the $(3+2)$ mechanism of addition of the TAC across the ethylene derivative is the reaction route that proceeds regio-selectively to afford $\mathbf{P 2 C}$ through TS2C. Figure 5 shows that the formation of P2D is the most favorable reaction route occurring along the $(4+3)$ mechanism of addition. The formation of P2D proceeds with the initial construction of INT2D through TS2D with an activation energy of $13.4 \mathrm{kcal} / \mathrm{mol}$ follow by cyclization of INT2D through TS4D with an activation barrier of $13.4 \mathrm{kcal} / \mathrm{mol}$. Similar to the parent reaction, the formation of INT2D through TS2D is thermodynamically and kinetically favored over the reaction channel that proceeds to generate INT1D.

The effects of different electron-donating groups (EDGs $\left.=\mathrm{CH}_{3}, \mathrm{NH}_{2}, \mathrm{OH}\right)$ and electronwithdrawing groups $\left(\mathrm{EWGs}=\mathrm{Br}, \mathrm{Cl}, \mathrm{CN}\right.$, ) on the TAC $\left(\mathbf{A 2}, \mathrm{R}^{3}=\mathrm{CH}_{3}, \mathrm{R}^{2}=\mathrm{EDGs}\right.$, EWGs) have also been examined. From tables 2 and 3 , the $(3+2)$ cycloaddition remains the most favorable mechanism of the addition of the substituted TAC $\left(\mathbf{A 2}, \mathrm{R}^{2}=\right.$ EDGs, EWGs, $\left.\mathrm{R}^{3}=\mathrm{CH}_{3},\right)$ across the ethylene derivative. This $(3+2)$ cycloaddition reaction is completely chemoselective along the thiocarbonyl group in the ethylene derivative. The formation of P2A through TS2A is the most 
favorable reaction for the $\mathbf{A 1}\left(\mathrm{R}^{1}=\mathrm{Ph}\right)$ with nitrilimine derivatives (A2) irrespective of the nature of the substituent on the TAC, and the closest competing reaction route proceeds to afford its regioisomer P1A through TS1A. Evident from table 2, the pathway that proceeds to furnish P2C through TS2C remains the least kinetically favored reaction route for all $(3+2)$ cycloaddition reactions considered. Even though a slight increase in activation energies is observed for phenyl substituent on the TAC $\left(\mathbf{A 2}, \mathrm{R}^{2}=\mathrm{Ph}, \mathrm{R}^{3}=\mathrm{CH}_{3}\right)$, the energetic trends remain the same. The formation of P2D is the most favored reaction channel for all the $(4+3)$ cycloaddition reactions considered. 


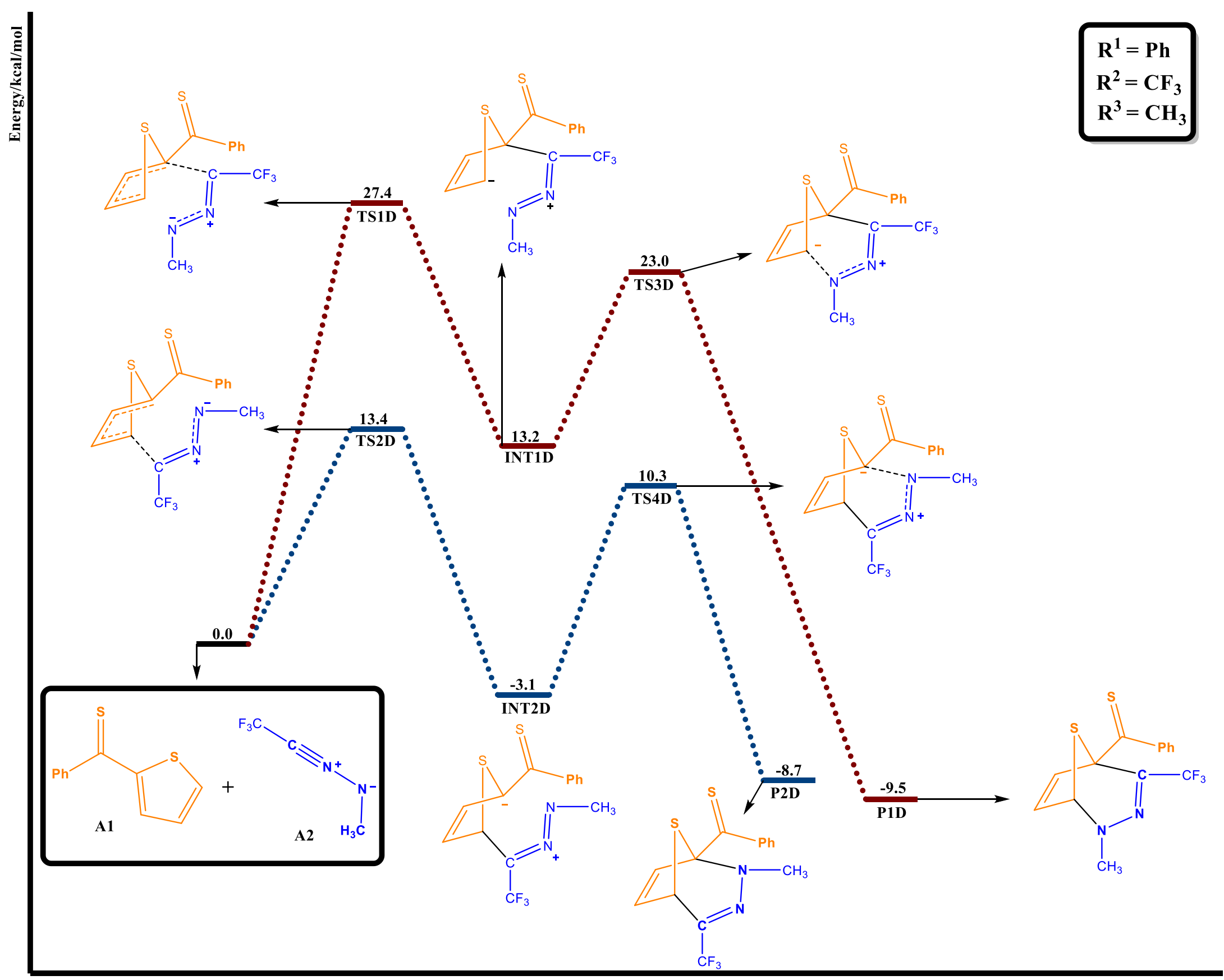

Reaction Coordinate

Figure 5: Energy profile for the $(4+3)$ cycloaddition reaction of phenyl(thiophen-2-yl) methanethione $\left(\mathbf{A 1}, \mathrm{R}^{1}=\mathrm{Ph}\right)$ with $N$-methyl$C$-trifluoromethyl nitrilimine $\left(\mathrm{A} 2, \mathrm{R}^{2}=\mathrm{CF} 3, \mathrm{R}^{3}=\mathrm{CH}_{3}\right)$ in the gas phase at the B3LYP/6-311G $(\mathrm{d}, \mathrm{p})$, level of theory. 
Table 2: Activation energies for the 32CA reaction between Phenyl(thiophen-2-yl)methanethiones and $N$-methyl- $C$-substituted nitrilimines. All energies are in $\mathrm{kcal} / \mathrm{mol}$.

\begin{tabular}{lllllllllllllll}
\hline \multicolumn{2}{l}{$\begin{array}{l}\text { SUBSTITUNTS } \\
\mathbf{R}^{\mathbf{1}}\end{array}$} & $\mathbf{R}^{\mathbf{2}}$ & $\mathbf{R}^{\mathbf{3}}$ & & & & & & & & & & & \\
\hline $\mathrm{Ph}$ & $\mathrm{H}$ & $\mathrm{CH}_{3}$ & 9.9 & 5.8 & 19.9 & 14.8 & 15.3 & 22.4 & -25.1 & -33.9 & -28.8 & -27.7 & -20.0 & -19.6 \\
$\mathrm{Ph}$ & $\mathrm{CH}_{3}$ & $\mathrm{CH}_{3}$ & 8.0 & 3.9 & 18.0 & 14.3 & 13.4 & 20.9 & -24.2 & -35.1 & -29.9 & -29.0 & -21.2 & -18.1 \\
$\mathrm{Ph}$ & $\mathrm{NH}_{2}$ & $\mathrm{CH}_{3}$ & 6.0 & 1.8 & 14.1 & 11.8 & 11.5 & 16.9 & -26.2 & -34.1 & -31.0 & -29.7 & -22.8 & -19.0 \\
$\mathrm{Ph}$ & $\mathrm{OH}$ & $\mathrm{CH}_{3}$ & 5.0 & 2.2 & 15.3 & 11.7 & 11.3 & 15.8 & -33.0 & -40.7 & -38.2 & -37.1 & -29.4 & -24.8 \\
$\mathrm{Ph}$ & $\mathrm{Br}$ & $\mathrm{CH}_{3}$ & 9.2 & 6.1 & 17.8 & 14.2 & 14.1 & 21.1 & -25.2 & -35.4 & -32.2 & -30.5 & -23.0 & -18.7 \\
$\mathrm{Ph}$ & $\mathrm{Cl}$ & $\mathrm{CH}_{3}$ & 8.0 & 4.2 & 16.4 & 12.8 & 13.0 & 19.7 & -28.7 & -38.1 & -35.3 & -33.7 & -26.2 & -22.2 \\
$\mathrm{Ph}$ & $\mathrm{CN}$ & $\mathrm{CH}_{3}$ & 11.2 & 5.6 & 19.2 & 17.6 & 18.2 & 22.5 & -23.3 & -32.6 & -30.1 & 27.7 & -20.1 & -17.4 \\
$\mathrm{Ph}$ & $\mathrm{CF}$ & $\mathrm{CH}_{3}$ & 11.1 & 4.0 & 18.4 & 12.7 & 15.4 & 23.5 & -25.4 & -36.4 & -33.8 & -31.5 & -28.0 & -20.2 \\
$\mathrm{Ph}$ & $\mathrm{Ph}$ & $\mathrm{CH}_{3}$ & 15.5 & 10.0 & 24.0 & 20.8 & 20.7 & 26.3 & -15.1 & -29.4 & -25.0 & -23.5 & -14.7 & -9.9 \\
\hline
\end{tabular}

Table 3: Activation energies for the $(4+3)$ cycloaddition reaction between Phenyl(thiophen-2-yl)methanethiones and $N$-methyl- $C$ substituted nitrilimines. All energies are in $\mathrm{kcal} / \mathrm{mol}$.

\begin{tabular}{lllllllllll}
\hline \multicolumn{2}{l}{$\begin{array}{l}\text { SUBSTITUENTS } \\
\mathbf{R}^{\mathbf{1}}\end{array}$} & $\mathbf{R}^{\mathbf{2}}$ & TS1D & TS2D & TS3D & TS4D & INT1D & INT2D & P1D & P2D \\
\hline $\mathrm{Ph}$ & $\mathrm{H}$ & $\mathrm{CH}_{3}$ & 28.9 & 14.4 & 12.7 & 18.5 & 16.2 & -1.0 & -1.8 & -3.8 \\
$\mathrm{Ph}$ & $\mathrm{CH}_{3}$ & $\mathrm{CH}_{3}$ & 27.7 & 14.3 & 7.2 & 18.5 & 20.5 & -1.1 & -5.9 & -3.8 \\
$\mathrm{Ph}$ & $\mathrm{NH}_{2}$ & $\mathrm{CH}_{3}$ & 22.9 & 12.5 & 5.8 & 13.2 & 17.1 & -2.4 & -8.3 & -4.6 \\
$\mathrm{Ph}$ & $\mathrm{OH}$ & $\mathrm{CH}_{3}$ & - & 12.1 & 8.2 & 13.3 & 10.9 & -9.4 & -14.6 & -14.4 \\
$\mathrm{Ph}$ & $\mathrm{Br}$ & $\mathrm{CH}_{3}$ & 27.4 & 14.8 & 7.4 & 15.6 & 17.7 & -2.6 & -9.0 & -8.5 \\
$\mathrm{Ph}$ & $\mathrm{Cl}$ & $\mathrm{CH}_{3}$ & 25.2 & 13.2 & 7.4 & 15.4 & 14.3 & -5.5 & -12.3 & -11.4 \\
$\mathrm{Ph}$ & $\mathrm{CN}$ & $\mathrm{CH}_{3}$ & 26.8 & 15.3 & 17.3 & 17.8 & 5.6 & 0.9 & -7.4 & -5.1 \\
$\mathrm{Ph}$ & $\mathrm{CF}$ & $\mathrm{CH}_{3}$ & 27.4 & 13.4 & 9.8 & 13.4 & 13.2 & -3.1 & -9.5 & -8.7 \\
$\mathrm{Ph}$ & $\mathrm{Ph}$ & $\mathrm{CH}_{3}$ & 36.2 & 17.8 & 7.0 & 21.0 & 27.2 & 4.9 & 2.6 & 2.4 \\
\hline
\end{tabular}




\subsection{Reaction of Thiophene-2-carbothialdehyde Derivatives with $N$-methyl- $C$ - trifluoromethyl nitrilimine.}

Tables 4 and 5 show the results for the $(3+2)$ and $(4+3)$ cycloaddition reactions for $N$-methyl$C$-trifluoromethyl nitrilimine $\mathbf{A 2}\left(\mathrm{R}^{2}=\mathrm{CF}_{3}, \mathrm{R}^{3}=\mathrm{CH}_{3}\right)$ and thiophene-2-carbothialdehyde derivatives $\mathbf{A 1}\left(\mathrm{R}^{1}=\right.$ EDGs, EWGs) at the B3LYP/6-311G $(\mathrm{d}, \mathrm{p})$ level of theory. In all reactions considered, the $(3+2)$ cycloaddition proceeds via an asynchronous one-step mechanism while the $(4+3)$ cycloaddition goes through a two-step mechanism.

From tables 4 and 5, the reaction of thiophene-2-carbothialdehyde $\mathbf{A 1}\left(\mathrm{R}^{1}=\mathrm{H}\right)$ with $N$-methyl- $C$ trifluoromethyl nitrilimine $\left(\mathbf{A 2}, \mathrm{R}^{2}=\mathrm{CF}_{3}, \mathrm{R}^{3}=\mathrm{CH}_{3}\right.$, ) favors the $(3+2)$ cycloaddition mechanism with the formation of P2A through TS2A with an activation energy of $3.3 \mathrm{kcal} / \mathrm{mol}$ being the most kinetically preferred reaction route. The formation of P1A through TS1A with an activation barrier of $5.7 \mathrm{kcal} / \mathrm{mol}$ is the closest competing pathway. The formation of P2B through TS2B is favored over the reaction route that proceeds to afford its regioisomer P1B through TS1B by $4.2 \mathrm{kcal} / \mathrm{mol}$ for the reaction of $\mathbf{A 1}\left(\mathrm{R}^{1}=\mathrm{H}\right)$ with $\mathbf{A 2}\left(\mathrm{R}^{2}=\mathrm{CF}_{3}, \mathrm{R}^{3}=\mathrm{CH}_{3}\right)$. From table 5, the two-step $(4+3)$ cycloaddition reaction between $\mathbf{A 1}\left(\mathrm{R}^{1}=\mathrm{H}\right)$ and $\mathbf{A 2}\left(\mathrm{R}^{2}=\mathrm{CF}_{3}, \mathrm{R}^{3}=\mathrm{CH}_{3}\right)$ favors the construction of P2D. The first step corresponds to the formation of intermediate INT2D via TS1D with an activation energy of $13.8 \mathrm{kcal} / \mathrm{mol}$ followed by cyclization of INT2D through TS4D to afford

P2D. The formation of INT1D via TS1D proceeds with an activation energy of $26.2 \mathrm{kcal} / \mathrm{mol}$ followed by cyclization of INT1D through TS3D with an activation energy of $4.4 \mathrm{kcal} / \mathrm{mol}$ to afford P1D. The mechanistic effects of EDGs $\left(\mathrm{R}^{3}=\mathrm{CH} 3, \mathrm{CH} 2 \mathrm{CH} 3, \mathrm{NH} 2, \mathrm{OH}, \mathrm{Cyc}\right)$ and EWGs $\left(\mathrm{R}^{3}=\mathrm{Cl}, \mathrm{CN}\right)$ on the reaction of $\mathbf{A 1}\left(\mathrm{R}^{1}=\right.$ EDGs, EWGs $)$ with $\mathbf{A 2}\left(\mathrm{R}^{2}=\mathrm{CF}_{3}, \mathrm{R}^{3}=\mathrm{CH}_{3}\right)$ have also been study. With regards to the reaction of $\mathbf{A 1}\left(\mathrm{R}^{1}=\mathrm{H}\right)$ and $\mathbf{A 2}\left(\mathrm{R}^{2}=\mathrm{CF}_{3}, \mathrm{R}^{3}=\mathrm{CH}_{3}\right)$, a slight variation in both activation and reaction energies were observed for the reaction of $\mathbf{A 1}\left(\mathrm{R}^{1}=\right.$ EDGs, EWGs) with $\mathbf{A 2}\left(\mathrm{R}^{2}=\mathrm{CF}_{3}, \mathrm{R}^{3}=\mathrm{CH}_{3}\right)$ but the energetic patterns remain the same. 
Table 4: Activation for the 32CA cycloaddition reaction between $N$-methyl- $C$-trifluoromethyl nitrilimine and thiophene-2carbothialdehyde derivatives. All energies are in $\mathrm{kcal} / \mathrm{mol}$.

\begin{tabular}{|c|c|c|c|c|c|c|c|c|c|c|c|c|c|c|}
\hline \multicolumn{3}{|c|}{ SUBSTITUENTS } & \multirow[t]{2}{*}{ TS1A } & \multirow[t]{2}{*}{ TS2A } & \multirow[t]{2}{*}{ TS1B } & \multirow[t]{2}{*}{ TS2B } & \multirow[t]{2}{*}{ TS1C } & \multirow[t]{2}{*}{ TS2C } & \multirow[t]{2}{*}{ P1A } & \multirow[t]{2}{*}{ P2A } & \multirow[t]{2}{*}{ P1B } & \multirow[t]{2}{*}{ P2B } & \multirow[t]{2}{*}{ P1C } & \multirow[t]{2}{*}{ P2C } \\
\hline $\mathbf{R}^{1}$ & $\mathbf{R}^{2}$ & $\mathbf{R}^{3}$ & & & & & & & & & & & & \\
\hline $\mathrm{H}$ & $\mathrm{CF}_{3}$ & $\mathrm{CH}_{3}$ & 5.7 & 3.3 & 17.2 & 13.0 & 14.1 & 14.2 & -33.1 & -41.2 & -32.9 & -31.1 & -29.7 & -20.9 \\
\hline $\mathrm{CH}_{3}$. & $\mathrm{CF}_{3}$ & $\mathrm{CH}_{3}$ & 8.6 & 4.6 & 16.7 & 13.3 & 14.5 & 14.7 & -29.8 & -38.8 & -33.2 & -31.2 & -30.6 & -20.8 \\
\hline $\mathrm{CH}_{2} \mathrm{CH}_{3}$ & $\mathrm{CF}_{3}$ & $\mathrm{CH}_{3}$ & 8.1 & 4.1 & 16.5 & 13.4 & 14.3 & 14.8 & -29.1 & -38.7 & -33.4 & -31.2 & -31.1 & -21.2 \\
\hline $\mathrm{NH}_{2}$ & $\mathrm{CF}_{3}$ & $\mathrm{CH}_{3}$ & 9.8 & 5.7 & 15.6 & 13.7 & 15.2 & 14.1 & -19.5 & -31.5 & -34.3 & 32.1 & -36.5 & -30.2 \\
\hline $\mathrm{OH}$ & $\mathrm{CF}_{3}$ & $\mathrm{CH}_{3}$ & 9.5 & 5.2 & 17.2 & 13.6 & 14.3 & 13.9 & -19.7 & -32.3 & -32.8 & -31.3 & -30.4 & -23.4 \\
\hline${ }^{\mathrm{a}} \mathrm{Cyc}$ & $\mathrm{CF}_{3}$ & $\mathrm{CH}_{3}$ & 9.8 & 8.0 & 18.0 & 13.1 & 14.7 & 14.4 & -27.7 & -35.5 & -33.5 & -31.4 & -31.8 & -22.5 \\
\hline $\mathrm{Cl}$ & $\mathrm{CF}_{3}$ & $\mathrm{CH}_{3}$ & 10.0 & 6.0 & 18.5 & 13.0 & 14.0 & 11.8 & -29.3 & -44.2 & -32.2 & -30.6 & -29.1 & -21.1 \\
\hline $\mathrm{CN}$ & $\mathrm{CF}_{3}$ & $\mathrm{CH}_{3}$ & 6.6 & 1.0 & 19.3 & 12.1 & 12.6 & 11.3 & -26.3 & -36.5 & -32.2 & -30.9 & -28.7 & -20.4 \\
\hline
\end{tabular}

Table 5: Activation for the $(4+3)$ cycloaddition reaction between $N$-methyl- $C$-trifluoromethyl nitrilimine and thiophene-2carbothialdehyde derivatives. All energies are in $\mathrm{kcal} / \mathrm{mol}$.

\begin{tabular}{|c|c|c|c|c|c|c|c|c|c|c|}
\hline \multicolumn{3}{|c|}{ SUBSTITUENTS } & \multirow[t]{2}{*}{ TS1D } & \multirow[t]{2}{*}{ TS2D } & \multirow[t]{2}{*}{ TS3D } & \multirow[t]{2}{*}{ TS4D } & \multirow[t]{2}{*}{ INT1D } & \multirow[t]{2}{*}{ INT2D } & \multirow[t]{2}{*}{ P1D } & \multirow[t]{2}{*}{ P2D } \\
\hline $\mathbf{R}^{1}$ & $\mathbf{R}^{2}$ & $\mathbf{R}^{3}$ & & & & & & & & \\
\hline $\mathrm{H}$ & $\mathrm{CF}_{3}$ & $\mathrm{CH}_{3}$ & 26.2 & 13.8 & 4.4 & 8.0 & 16.4 & -1.9 & -10.8 & -9.6 \\
\hline $\mathrm{CH}_{3}$. & $\mathrm{CF}_{3}$ & $\mathrm{CH}_{3}$ & 26.3 & - & 5.3 & 7.1 & 15.2 & -2.2 & -10.0 & -10.5 \\
\hline $\mathrm{CH}_{2} \mathrm{CH}_{3}$ & $\mathrm{CF}_{3}$ & $\mathrm{CH}_{3}$ & 25.8 & 13.2 & 4.9 & 7.2 & 14.7 & -2.4 & -10.1 & -9.5 \\
\hline $\mathrm{NH}_{2}$ & $\mathrm{CF}_{3}$ & $\mathrm{CH}_{3}$ & 20.0 & 12.0 & 7.5 & 3.2 & 9.7 & -0.7 & -12.8 & -14.8 \\
\hline $\mathrm{OH}$ & $\mathrm{CF}_{3}$ & $\mathrm{CH}_{3}$ & 22.5 & 12.7 & - & - & 13.7 & -1.0 & -11.8 & -12.2 \\
\hline${ }^{\mathrm{a}} \mathrm{Cyc}$ & $\mathrm{CF}_{3}$ & $\mathrm{CH}_{3}$ & 26.0 & 13.3 & 6.3 & 6.5 & 13.2 & -2.4 & -9.8 & -11.6 \\
\hline $\mathrm{Cl}$ & $\mathrm{CF}_{3}$ & $\mathrm{CH}_{3}$ & 28.6 & 12.9 & 5.9 & 9.5 & 15.8 & -2.3 & -8.9 & -9.2 \\
\hline $\mathrm{CN}$ & $\mathrm{CF}_{3}$ & $\mathrm{CH}_{3}$ & 26.1 & 12.8 & 5.9 & 10.1 & 17.3 & -3.3 & -8.7 & -8.2 \\
\hline
\end{tabular}




\subsection{Global Reactivity Indices Analysis of the Reaction of Thiophene-2-carbothialdehyde Derivatives and $C, N$-disubstituted Nitrilimine Derivatives}

In this section, we employ various conceptual tools to analyze the reaction of $\mathbf{A 1}$ and $\mathbf{A 2}$. The electronic chemical potential $(\mu)$, chemical hardness $(\eta)$, global electrophilicity $(\omega)$, maximum electronic charge transfer $\left(\Delta \mathrm{N}_{\max }\right)$ and nucleophilicity values $(\mathrm{N})$ of the various derivatives of nitrilimine (A2) and thiophene-2-carbothialdehyde (A1) have been calculated and the results displayed in tables 6 and 7 respectively. The $\mu$ for $\mathbf{A 1}\left(R^{1}=P h\right)$ is $-4.41 \mathrm{eV}$ and that of $\mathbf{A 2}\left(R^{2}=\right.$ $\left.\mathrm{CF}_{3}, \mathrm{R}^{3}=\mathrm{Ph}\right)$ thus $\mathbf{A 2}\left(\mathrm{R}^{2}=\mathrm{CF}_{3}, \mathrm{R}^{3}=\mathrm{Ph}\right)$ present a similar chemical potential as $\mathbf{A 1}\left(\mathrm{R}^{1}=\mathrm{Ph}\right)$. Consequently, it is expected that the reaction of $\mathbf{A 1}\left(\mathrm{R}^{1}=\mathrm{Ph}\right)$ and $\mathbf{A 2}\left(\mathrm{R}^{2}=\mathrm{CF}_{3}, \mathrm{R}^{3}=\mathrm{Ph}\right)$ will present low polar character. This observation is consistent with the calculated GEDT values of the competitive 32CA reaction pathways discussed in section 3.1. From table 6, EWGs $\left(\mathrm{R}^{2}=\mathrm{CF}_{3}\right.$, $\mathrm{Br}, \mathrm{Cl}, \mathrm{CN}$,) on the nitrilimine (A2) increases the electronic chemical potential values relative to A2 $\left(\mathrm{R}^{2}=\mathrm{CF}_{3}, \mathrm{R}^{3}=\mathrm{Ph}\right)$ thus making the TACs strong electron-acceptor molecules. The order of electron-withdrawing ability of the various nitrilimine derivatives is given as; $-\mathrm{CF}_{3}<-\mathrm{Cl}<-\mathrm{Br}<$ -CN. Contrary to EWGs, EDGs $\left(\mathrm{R}^{2}=\mathrm{CH}_{3}, \mathrm{NH}_{2}, \mathrm{OH}, \mathrm{Ph}\right)$ reduces chemical potential values relative to $\mathbf{A 2}\left(\mathrm{R}^{2}=\mathrm{CF}_{3}, \mathrm{R}^{3}=\mathrm{Ph}\right)$ hence making the TACs strongly electron-donating molecules. From table 7 , the increase in the order of the electronic chemical potential for the various substituents on the ethylene derivative $\mathbf{A 1}$ is given in the order $-\mathrm{NH}_{2}<\mathrm{Cyc}<\mathrm{CH}_{2} \mathrm{CH}_{3}=\mathrm{Ph}<\mathrm{OH}$ $<\mathrm{H}<\mathrm{CH}_{3}<\mathrm{Cl}<\mathrm{CN}$. The increase in the electron-withdrawing character of $-\mathrm{Cl}$ and $-\mathrm{CN}$ accounts for the significant decrease in their electronic chemical potential.

The global electrophilicity $(\omega)$ [37] and maximum electronic charge transfer $\left(\Delta \mathrm{N}_{\max }\right)$ [49] have become a useful tool in the analysis of the reactivity of species participating in polar organic reactions. The electrophilicity $\omega$ scale permits the classification of reacting organic species as strong electrophiles with $\omega>1.5 \mathrm{eV}$, moderate electrophiles with $\omega>0.8 \mathrm{eV}$ and nucleophiles (marginal electrophiles) with $\omega<0.8 \mathrm{eV}$. The $\omega$ values of $\mathbf{A 1}\left(\mathrm{R}^{1}=\mathrm{Ph}\right)$ is $3.07 \mathrm{eV}$ and $\mathbf{A 2}\left(\mathrm{R}^{2}=\right.$ $\mathrm{CF}_{3}, \mathrm{R}^{3}=\mathrm{Ph}$ ) is $2.23 \mathrm{eV}$. Thus, both $\mathbf{A 1}$ and $\mathbf{A 2}$ are strong electrophiles. The $\Delta \mathrm{N}_{\max }$ value for $\mathbf{A 1}$ 
$\left(\mathrm{R}^{1}=\mathrm{Ph}\right)$ is $1.39 \mathrm{eV}$ and $\mathbf{A} 2\left(\mathrm{R}^{2}=\mathrm{CF}_{3}, \mathrm{R}^{3}=\mathrm{Ph},\right)$ is $3.77 \mathrm{eV}$. The $\omega$ and $\Delta \mathrm{N}_{\max }$ values suggest that $\mathbf{A 1}\left(\mathrm{R}^{1}=\mathrm{Ph}\right)$ is both a better electrophile and nucleophile than $\mathbf{A} 2\left(\mathrm{R}^{2}=\mathrm{CF}_{3}, \mathrm{R}^{3}=\mathrm{Ph}\right)$ thus $\mathbf{A 1}\left(\mathrm{R}^{1}\right.$ $=\mathrm{Ph})$. EDGs on the ethylene derivative $\mathbf{A 1}$ significantly reduce the $\omega$ value relative to $\mathbf{A} \mathbf{1}\left(\mathrm{R}^{1}=\right.$ $\mathrm{Ph})$ whereas EWGs on $\mathbf{A 1}$ increase the $\omega$ value. $\mathbf{A 2}\left(\mathrm{R}^{2}=\mathrm{H}, \mathrm{CH} 3, \mathrm{NH}_{2}, \mathrm{R}^{3}=\mathrm{CH}_{3}\right)$ are marginal electrophiles, $\mathrm{A} \mathbf{2}\left(\mathrm{R}^{2}=\mathrm{OH}, \mathrm{Cl}, \mathrm{CF} 3, \mathrm{Ph}, \mathrm{CN}, \mathrm{R}^{3}=\mathrm{CH}_{3}\right)$ are moderate electrophiles and $\mathbf{A} \mathbf{2}\left(\mathrm{R}^{2}=\right.$ $\mathrm{Br}, \mathrm{R}^{3}=\mathrm{CH}_{3}$ ) is a strong electrophile as seen from table 6. From table 7, all the thiophene-2carbothialdehyde derivatives (A1) considered in this study are strong electrophiles.

By examining the nucleophilicity values (N) [41] provided in table $6, \mathbf{A 2}\left(\mathrm{R}^{2}=\mathrm{CF} 3, \mathrm{R}^{3}=\mathrm{CH}_{3}\right)$ has $\mathrm{N}$ value of $0.81 \mathrm{eV}$ and is the poorest among the nitrilimine derivatives, while $\mathbf{A} 2\left(\mathrm{R}^{2}=\mathrm{Ph}, \mathrm{R}^{3}=\right.$ $\mathrm{CH}_{3}$ ) with $\mathrm{N}$ value of $3.91 \mathrm{eV}$ represents the best nucleophile. For $N$-methyl- $C$-substituted nitrilimine, EDGs $\mathbf{A 2}\left(\mathrm{R}^{2}=\mathrm{CH}_{3}, \mathrm{NH}_{2}, \mathrm{OH}, \mathrm{R}^{3}=\mathrm{CH}_{3}\right)$ tend to increase the nucleophilicity (except, $\left.\mathrm{R}^{2}=\mathrm{OH}\right)$ in the order $\mathrm{CH}_{3}>\mathrm{NH}_{2}>\mathrm{OH}$ relative to $\mathbf{A} 2\left(\mathrm{R}^{2}=\mathrm{H}, \mathrm{R}^{3}=\mathrm{CH}_{3}\right)$. In contrast to EDGs, EWDs on the TAC A2 $\left(\mathrm{R}^{2}=\mathrm{Br}, \mathrm{Cl}, \mathrm{CN}, \mathrm{CF}_{3}, \mathrm{R}^{3}=\mathrm{CH}_{3}\right)$ reduces the $\mathrm{N}$ value in the order $\mathrm{Br}<\mathrm{Cl}<$ $\mathrm{CN}<\mathrm{CF}_{3}$. Aromatic substituent on the TAC A2 $\left(\mathrm{R}^{2}=\mathrm{Ph}, \mathrm{R}^{3}=\mathrm{CH}_{3}\right)$ drastically increase the $\mathrm{N}$ value of the TAC. The $\mathrm{N}$ values shown in table 7 for various substituents on the $\mathbf{A 1}$ is given in the order $\mathrm{NH}_{2}>\mathrm{Cyc}>\mathrm{Ph}>\mathrm{CH}_{2} \mathrm{CH}_{3}>\mathrm{H}>\mathrm{OH}>\mathrm{Cl}>\mathrm{CN}>\mathrm{CH}_{3}$. The observed $\mathrm{N}$ values are consistent with the observed reactivity patterns. 
Table 6: Global reactivity indices for the various derivatives of nitrilimine (A2). Orbital energies are in $\mathrm{eV}$.

\begin{tabular}{lllllllll}
\hline \multicolumn{2}{l}{ SUBSTRATE (A2) } & HOMO & LUMO & $\boldsymbol{\mu}$ & $\boldsymbol{\eta}$ & $\boldsymbol{\omega}$ & $\Delta \boldsymbol{N}_{\max }$ & $\mathbf{N}$ \\
$\mathbf{R}^{2}$ & $\mathbf{R}^{3}$ & & & & & & & \\
\hline $\mathrm{H}$ & $\mathrm{CH}_{3}$ & -7.62 & 0.53 & -3.54 & 8.15 & 0.77 & 6.52 & 1.75 \\
$\mathrm{CH}_{3}$ & $\mathrm{CH}_{3}$ & -6.94 & 0.85 & -3.05 & 7.79 & 0.60 & 6.84 & 2.41 \\
$\mathrm{NH}_{2}$ & $\mathrm{CH}_{3}$ & -7.29 & 0.40 & -3.44 & 7.69 & 0.77 & 6.39 & 2.08 \\
$\mathrm{OH}$ & $\mathrm{CH}_{3}$ & -7.70 & 0.23 & -3.73 & 7.93 & 0.88 & 6.23 & 1.67 \\
$\mathrm{Br}$ & $\mathrm{CH}_{3}$ & -8.02 & -1.26 & -4.64 & 6.76 & 1.59 & 4.73 & 1.34 \\
$\mathrm{Cl}$ & $\mathrm{CH}_{3}$ & -8.13 & -1.01 & -4.57 & 7.11 & 1.47 & 4.98 & 1.24 \\
$\mathrm{CN}$ & $\mathrm{CH}_{3}$ & -8.42 & -1.00 & -4.72 & 7.42 & 1.50 & 4.99 & 0.94 \\
$\mathrm{CF}$ & $\mathrm{CH}_{3}$ & -8.56 & -0.35 & -4.45 & 8.21 & 1.21 & 5.65 & 0.81 \\
$\mathrm{Ph}$ & $\mathrm{CH}_{3}$ & -5.46 & -1.06 & -3.26 & 4.40 & 1.21 & 4.93 & 3.91 \\
$\mathrm{CF}_{3}$ & $\mathrm{Ph}$ & -6.58 & -2.23 & -4.40 & 4.35 & 2.23 & 3.77 & 2.79 \\
\hline
\end{tabular}

Table 7: Global reactivity indices for the various derivatives of thiophene-2-carbothialdehyde derivatives (A1). Orbital energies are in $\mathrm{eV}$.

\begin{tabular}{llllllll}
\hline SUBSTRATE (A1) & HOMO & LUMO & $\boldsymbol{\mu}$ & $\boldsymbol{\eta}$ & $\boldsymbol{\omega}$ & $\boldsymbol{\Delta} \boldsymbol{N}_{\max }$ & $\mathbf{N}$ \\
$\mathbf{\mathbf { R } ^ { 1 }}$ & & & & & & & \\
\hline $\mathrm{H}$ & -6.22 & -2.91 & -4.56 & 3.31 & 3.15 & 1.38 & 3.15 \\
$\mathrm{CH}_{3}$. & -7.63 & -1.82 & -4.73 & 5.80 & 1.92 & 0.81 & 1.74 \\
$\mathrm{CH}_{2} \mathrm{CH}_{3}$ & -6.07 & -2.76 & -4.41 & 3.31 & 2.94 & 1.33 & 3.30 \\
$\mathrm{NH}_{2}$ & -5.95 & -2.13 & -4.04 & 3.82 & 2.13 & 1.06 & 3.42 \\
$\mathrm{OH}$ & -6.54 & -2.5 & -4.53 & 4.02 & 2.56 & 1.13 & 2.82 \\
$\mathrm{Cyc}$ & -6.09 & -2.65 & -4.37 & 3.43 & 2.78 & 1.27 & 3.38 \\
$\mathrm{Cl}$ & -6.76 & -3.18 & -4.97 & 3.58 & 3.45 & 1.39 & 2.61 \\
$\mathrm{CN}$ & -6.92 & -3.78 & -5.35 & 3.14 & 4.57 & 1.71 & 2.44 \\
$\mathrm{Ph}$ & -5.99 & -2.83 & -4.41 & 3.17 & 3.07 & 1.39 & 3.37 \\
\hline
\end{tabular}




\subsection{Analysis of Chemoselectivity with Local Reactivity Indices.}

In this section, we employ the local electrophilic $\left(P_{K}^{+}\right)$and nucleophilic $\left(P_{K}^{-}\right)$Parr functions [40] to analyze the chemoselectivity observed in the titled reaction. Figure 6 shows the atomic labels of the ethylene derivative $\left(\mathrm{A} 1, \mathrm{R}^{1}=\mathrm{Ph}\right)$ and $\mathrm{TAC}\left(\mathrm{A} 2, \mathrm{R}^{2}=\mathrm{CF}_{3}, \mathrm{R}^{3}=\mathrm{Ph}\right)$. The Mulliken atomic spin densities (ASD) analyses have been employed to investigate the origin of the chemoselectivity, and the results are shown in table 8 . These analyses allow the characterization of the most electrophilic and nucleophilic centers in a molecule. Within an ethylene derivative, the reaction center having the largest electron density is the ideal point of attachment by a TAC.

Analysis of the reaction centers present in the ethylene derivative with respect to the electrophilic Mulliken spin densities shows that, $\mathrm{C}_{1}=-0.019, \mathrm{C}_{2}=0.01, \mathrm{C}_{3}=-0.017, \mathrm{C}_{4}=0.016, \mathrm{C}_{5}=-0.060$ and $S_{2}=0.864$ and the nucleophilic Mulliken spin densities shows that, $C_{1}=0.188, C_{2}=-0.085$, $\mathrm{C}_{3}=0.205, \mathrm{C}_{4}=-0.092, \mathrm{C}_{5}=0.331$ and $\mathrm{S}_{2}=0.292$. The relatively large electron density present at $\mathrm{C}_{5}$ and $\mathrm{S}_{2}$ compared to other reaction sites accounts for the preferential addition of the TAC across the thiocarbonyl present in the ethylene derivative.

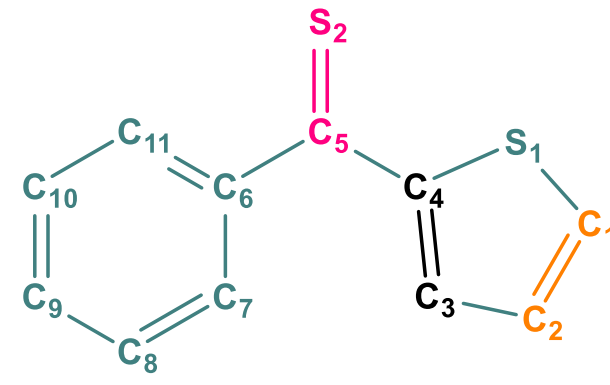

Ethylene Derivative

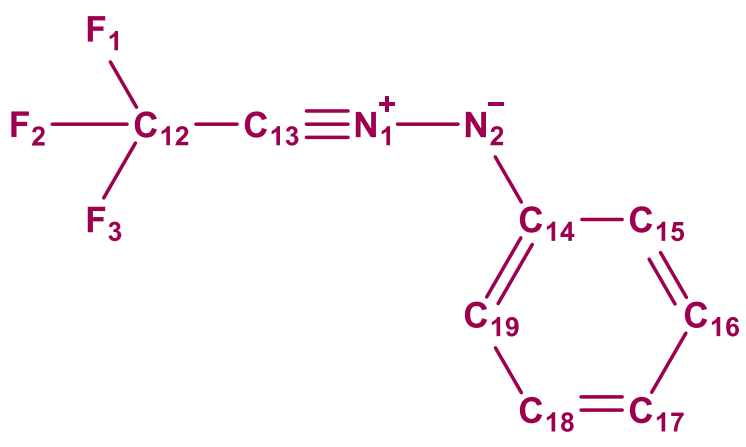

TAC

Figure 6: Atomic labels of Phenyl(thiophen-2-yl)methanethione (ethylene derivative) and $N$ phenyl- $C$-trifluoromethyl nitrilimine (TAC) 
Table 8: Mulliken atomic spin densities of Phenyl(thiophen-2-yl)methanethione (ethylene derivative) and $N$-phenyl- $C$-trifluoromethyl nitrilimine

\begin{tabular}{|c|c|c|c|c|c|}
\hline \multicolumn{4}{|c|}{ ETHYLENE DERIVATIVE } & \multicolumn{2}{|c|}{ TAC } \\
\hline & \multicolumn{2}{|c|}{ MULLIKEN } & & \multicolumn{2}{|c|}{ MULLIKEN } \\
\hline & ANION & CATION & & ANION & CATION \\
\hline $\mathrm{C}_{1}$ & 0.188 & -0.019 & $\mathrm{C}_{12}$ & 0.062 & -0.010 \\
\hline $\mathrm{C}_{2}$ & -0.085 & 0.010 & $\mathrm{C}_{13}$ & 0.502 & 0.235 \\
\hline $\mathrm{C}_{3}$ & 0.205 & -0.017 & $\mathrm{C}_{14}$ & -0.004 & 0.075 \\
\hline $\mathrm{C}_{4}$ & -0.092 & 0.016 & $\mathrm{C}_{15}$ & 0.009 & 0.196 \\
\hline $\mathrm{C}_{5}$ & 0.331 & -0.060 & $\mathrm{C}_{16}$ & 0.001 & -0.109 \\
\hline $\mathrm{C}_{6}$ & -0.046 & 0.092 & $\mathrm{C}_{17}$ & -0.007 & 0.352 \\
\hline $\mathrm{C}_{7}$ & 0.077 & -0.007 & $\mathrm{C}_{18}$ & 0.002 & -0.067 \\
\hline $\mathrm{C}_{8}$ & -0.039 & 0.028 & $\mathrm{C}_{19}$ & -0.003 & 0.149 \\
\hline $\mathrm{C}_{9}$ & 0.104 & 0.074 & $\mathbf{N}_{1}$ & 0.287 & 0.084 \\
\hline $\mathrm{C}_{10}$ & -0.042 & -0.031 & $\mathbf{N}_{2}$ & 0.126 & 0.283 \\
\hline $\mathrm{C}_{11}$ & 0.084 & 0.060 & $\mathbf{F}_{1}$ & -0.003 & 0.004 \\
\hline $\mathrm{S}_{1}$ & 0.053 & 0.006 & $F_{2}$ & 0.008 & 0.007 \\
\hline $\mathbf{S}_{2}$ & 0.292 & 0.854 & $\mathbf{F}_{3}$ & 0.014 & 0.001 \\
\hline
\end{tabular}




\subsection{Conclusion}

The reaction of phenyl(thiophen-2-yl)methanethione and $N$-phenyl- $C$-trifluoromethyl nitrilimine proceed through an asynchronous one-step 32CA reaction rather than a two-step $(4+3)$ cycloaddition and present low character for the addition of the TAC across the thiocarbonyl group. The TAC chemoselectively adds across the thiocarbonyl group present in the ethylene derivative to yield P2A. The formation of P2A has the highest calculated rate constant of $1.7 \times 10^{10} \mathrm{~s}^{-1}$ and is 141666 times faster than the closest competing pathway, which goes through TS1A to generate P1A. The two-step $(4+3)$ cycloaddition reaction occurs with an initial carbon-carbon formation between the reacting species. Significant selectivity between the various regioisomers was observed.

The reaction route that regio-selectively proceeds to afford P1A is the preferred pathway in all reactions considered irrespective of the substituents' effects on the ethylene derivative and TAC. Analysis of the electrophilic $\left(P_{K}^{+}\right)$and nucleophilic $\left(P_{K}^{-}\right)$Parr functions at the various reaction centers in the ethylene derivative shows that the TAC adds across the atomic centers with the largest atomic spin densities. The selectivities observed in the title reaction are kinetically controlled. Results from global electron density transfer (GEDT) reveal the low polar character in the 32CA reaction involving the cycloaddition of the nitrile imines to selected ethylene derivatives. 


\section{Acknowledgments}

This work was made possible in part by a grant of high performance computing resources from the South Africa's Centre for High-Performance Computing.

\section{Funding}

Koachie Health Systems (KHS) funded this project through the basic and computational sciences research fund (KHS/MQC/2640/2020).

\section{Competing Interest}

The authors declare that there is no conflict of interest whatsoever regarding the publication of this manuscript.

\section{Availability of data and material}

The data supporting this publication are included in the article and the electronic supporting information.

\section{Code availability}

Not Applicable

\section{Declarations}

The authors have no financial or proprietary interests in any material discussed in this article.

\section{Electronic Supporting Information}

The Supporting Information file provides cartesian coordinates of all optimized geometries, harmonic vibrational frequencies, and energetics for all intermediates and transition states considered in this study.

\section{ORCID}

George Baffour Pipim: https://orcid.org/0000-0002-4700-8005

Ernest Opoku: https://orcid.org/0000-0002-4271-6838

\section{References}

[1] Y. Lan, K.N. Houk, Mechanism and stereoselectivity of the stepwise 1,3-dipolar cycloadditions between a thiocarbonyl ylide and electron-deficient dipolarophiles: A computational investigation, J. Am. Chem. Soc. 132 (2010) 17921-17927. https://doi.org/10.1021/ja108432b.

[2] V. Nair, T.D. Suja, Intramolecular 1,3-dipolar cycloaddition reactions in targeted syntheses, Tetrahedron. 63 (2007) 12247-12275. https://doi.org/10.1016/j.tet.2007.09.065. 
[3] T. Brown, Deisign thinking, Harv. Bus. Rev. 86 (2008) 84-92. https://doi.org/10.1002/med.

[4] G.B. Pipim, E. Opoku, R. Tia, E. Adei, Peri-, Chemo-, Regio-, Stereo- and EnantioSelectivities of 1,3-dipolar cycloaddition reaction of C,N-Disubstituted nitrones with disubstituted 4-methylene-1,3-oxazol-5(4H)- one: A quantum mechanical study, J. Mol. Graph. Model. 97 (2020). https://doi.org/10.1016/j.jmgm.2020.107542.

[5] E. Opoku, G. Baffour Pipim, R. Tia, E. Adei, Mechanistic study of the tandem intramolecular $(4+2)$ /intermolecular $(3+2)$ cycloaddition reactions for the formation of polyaza- and polyisoxazolidine-steroids, J. Heterocycl. Chem. 57 (2020) 1748-1758. https://doi.org/10.1002/jhet.3900.

[6] G. Arhin, A.H. Adams, E. Opoku, R. Tia, E. Adei, 1, 3-Dipolar cycloaddition reactions of selected 1,3-dipoles with 7-isopropylidenenorbornadiene and follow-up thermolytic cleavage: A computational study, J. Mol. Graph. Model. 92 (2019) 267-279. https://doi.org/10.1016/j.jmgm.2019.08.004.

[7] Lan, Yu, and K. N. Houk, Mechanism and stereoselectivity of the stepwise 1, 3-dipolar cycloadditions between a thiocarbonyl ylide and electron-deficient dipolarophiles: a computational investigation." J. Am. Chem. Soc. 132.50 (2010): 17921-17927.

[8] D.H. Ess, K.N. Houk, Theory of 1,3-dipolar cycloadditions: Distortion/interaction and frontier molecular orbital models, J. Am. Chem. Soc. 130 (2008) 10187-10198. https://doi.org/10.1021/ja800009z.

[9] L. Fišera, R. Huisgen, I. Kalwinsch, E. Langhals, X. Li, G. Mloston, K. Polborn, J. Rapp, W. Sicking, R. Sustmann, New thione chemistry, Pure Appl. Chem. 68 (1996) 789-798. https://doi.org/10.1351/pac199668040789.

[10] S. Urinda, D. Kundu, A. Majee, in Water I ndium Triflate-Catalyzed One-Pot Synthesis of, Heteroat. Chem. 20 (2009) 232-234. https://doi.org/10.1002/hc.

[11] R. Huisgen, The Chemistry of Thiocarbonyl S-Sulfides, Tetrahedron. 53 (1997) 939-960.

[12] G. Mlostoń, P. Grzelak, M. Mikina, A. Linden, H. Heimgartner, Hetero-Diels - Alder reactions of hetaryl and aryl thioketones with acetylenic dienophiles, Beilstein J. Org. Chem. 11 (2015) 576-582. https://doi.org/10.3762/bjoc.11.63.

[13] R. Huisgen, L. Fisera, H. Giera, R. Sustmann, Thiones as Superdipolarophiles. Rates and Equilibria of Nitrone Cycloadditions to Thioketones, J. Am. Chem. Soc. 117 (1995) 96719678. https://doi.org/10.1021/ja00143a008.

[14] G. Mlostoń, H.F. Róza, A. Linden, H. Heimgartner, Synthesis of ferrocenyl-substituted 1,3dithiolanes via [3+2]-cycloadditions of ferrocenyl hetaryl thioketones with thiocarbonyl S-methanides, Beilstein J. Org. Chem. 12 (2016) 1421-1427. https://doi.org/10.3762/bjoc.12.136.

[15] Black, S. C., and K. G. Watson. Properties, of Some Nitrones and oxaziridines, (1973). "Nitrones and oxaziridines. IX. Cycloaddition reactions of nitrones with thioketones and the thermal and photochemical properties of some resulting 1, 4, 2-oxathiazolidines." Aust. J. Chem. 26.11 (1973): 2491-2504. https://doi.org/10.1071/CH9732491

[16] G. Mlostoń, E. Obijalska, M. Celeda, V. Mittermeier, A. Linden, H. Heimgartner, 1,3- 
Dipolar cycloadditions of fluorinated nitrones with thioketones, J. Fluor. Chem. 165 (2014) 27-32. https://doi.org/10.1016/j.jfluchem.2014.05.015.

[17] K. Shioji, A. Matsumoto, M. Takao, Y. Kurauchi, T. Shigetomi, Y. Yokomori, K. Okuma, Cycloadditions of 3,4-dihydro-2H-pyrrole N-oxide with thioketones and a selenoketone, Bull. Chem. Soc. Jpn. 80 (2007) 743-746. https://doi.org/10.1246/bcsj.80.743.

[18] G. Mlostoń, A. Michalak, A. Fruziński, M. Jasiński, Stereoselective 1,3-dipolar cycloadditions of thioketones to carbohydrate-derived nitrones, Tetrahedron Asymmetry. 27 (2016) 973-979. https://doi.org/10.1016/j.tetasy.2016.08.007.

[19] G. Mlostoń, P. Grzelak, R. Hamera-Fałdyga, M. Jasiński, P. Pipiak, K. Urbaniak, Ł. Albrecht, J. Hejmanowska, H. Heimgartner, Aryl, hetaryl, and ferrocenyl thioketones as versatile building blocks for exploration in the organic chemistry of sulfur, Phosphorus, $\begin{array}{llllll}\text { Sulfur Silicon } & \text { Relat. } & \text { Elem. } & \end{array}$ https://doi.org/10.1080/10426507.2016.1252368.

[20] A.K. Jain, S. Sharma, A. Vaidya, V. Ravichandran, R.K. Agrawal, 1,3,4-thiadiazole and its derivatives: A review on recent progress in biological activities, Chem. Biol. Drug Des. 81 (2013) 557-576. https://doi.org/10.1111/cbdd.12125.

[21] M. D. Hanwell, D. E. Curtis, D. C. Lonie, T. Vandermeersch, E. Zurek G. R. Hutchison; "Avogadro: An advanced semantic chemical editor, visualization, and analysis platform" J. Cheminformatics 2012, 4:17. https://doi.org/10.1186/1758-2946-4-17

[22] M. Clark, R.D. Cramer, N. Van Opdenbosch, Validation of the general purpose tripos 5.2 force field, J. Comput. Chem. 10 (1989) 982-1012. https://doi.org/10.1002/jcc.540100804.

[23] H.B. Schlegel, Optimization of equilibrium geometries and transition structures, J. Comput. Chem. 3 (1982) 214-218. https://doi.org/10.1002/jcc.540030212.

[24] K.N. Kudin, G.E. Scuseria, E. Cancès, A black-box self-consistent field convergence algorithm: One step closer, J. Chem. Phys. 116 (2002) 8255-8261. https://doi.org/10.1063/1.1470195.

[25] C.E. Dykstra, G. Frenking, K.S. Kim, G.E. Scuseria, Theory and Applications of Computational Chemistry, 1st ed., Elsevier, Amsterdam ;;Boston, 2005.

[26] H.P. Hratchian, H.B. Schlegel, Accurate reaction paths using a Hessian based predictorcorrector integrator, J. Chem. Phys. $120 \quad$ (2004) 9918-9924. https://doi.org/10.1063/1.1724823.

[27] H.P. Hratchian, H.B. Schlegel, Using Hessian updating to increase the efficiency of a Hessian based predictor-corrector reaction path following method, J. Chem. Theory Comput. 1 (2005) 61-69. https://doi.org/10.1021/ct0499783.

[28] G. Arhin, A.H. Adams, E. Opoku, R. Tia, E. Adei, 1, 3-Dipolar cycloaddition reactions of selected 1,3-dipoles with 7-isopropylidenenorbornadiene and follow-up thermolytic cleavage: A computational study, J. Mol. Graph. Model. 92 (2019) 267-279. https://doi.org/10.1016/j.jmgm.2019.08.004.

[29] E. Opoku, R. Tia, E. Adei, Versus [2 + 2] Addition: A Density Functional Theory Study on the Mechanistic Aspects of Transition Metal-Assisted Formation of 1,2-Dinitrosoalkanes, 
J. Chem. 2016 (2016) 10 pages. https://doi.org/10.1155/2016/4538696.

[30] J.B. Borketey, E. Opoku, R. Tia, E. Adei, The mechanisms of gallium-catalysed skeletal rearrangement of 1,6-enynes - Insights from quantum mechanical computations, J. Mol. Graph. Model. 94 (2020) 107476. https://doi.org/10.1016/j.jmgm.2019.107476.

[31] C.Y. Legault, C. Y. CYLview, (2009).

[32] M.J. Frisch, G.W. Trucks, H.B. Schlegel, G.E. Scuseria, M.A. Robb, J.R. Cheeseman, G. Scalmani, V. Barone, B. Mennucci, G.A. Petersson, Gaussian 09, revision b. 01, Gaussian, Inc., Wallingford, CT. 6492 (2009).

[33] K.N. Houk, B.R. Beno, M. Nendel, K. Black, H.Y. Yoo, S. Wilsey, J.K. Lee, Exploration of pericyclic reaction transition structures by quantum mechanical methods: Competing concerted and stepwise mechanisms, J. Mol. Struct. THEOCHEM. 398-399 (1997) 169179. https://doi.org/10.1016/S0166-1280(96)04970-6.

[34] J. Tirado-Rives, W.L. Jorgensen, Performance of B3LYP density functional methods for a large set of organic molecules, J. Chem. Theory Comput. 4 (2008) 297-306. https://doi.org/10.1021/ct700248k.

[35] S.E. Wheeler, A. Moran, S.N. Pieniazek, K.N. Houk, Accurate reaction enthalpies and sources of error in DFT Thermochemistry for aldol, mannich, and a-aminoxylation reactions, J. Phys. Chem. A. 113 (2009) 10376-10384. https://doi.org/10.1021/jp9058565.

[36] Y. Zhao, D.G. Truhlar, Density functionals with broad applicability in chemistry, Acc. Chem. Res. 41 (2008) 157-167. https://doi.org/10.1021/ar700111a.

[37] L.R. Domingo, M.J. Aurell, P. Pérez, R. Contreras, Quantitative characterization of the local electrophilicity of organic molecules. Understanding the regioselectivity on Diels-Alder reactions, J. Phys. Chem. A. 106 (2002) 6871-6875. https://doi.org/10.1021/jp020715j.

[38] R.G. Parr, L. V. Szentpály, S. Liu, Electrophilicity index, J. Am. Chem. Soc. 121 (1999) 1922-1924. https://doi.org/10.1021/ja983494x.

[39] T. Koopmans, Über die Zuordnung von Wellenfunktionen und Eigenwerten zu den Einzelnen Elektronen Eines Atoms, Physica. 1 (1934) 104-113. https://doi.org/10.1016/S0031-8914(34)90011-2.

[40] L.R. Domingo, P. Pérez, J.A. Sáez, Understanding the local reactivity in polar organic reactions through electrophilic and nucleophilic Parr functions, RSC Adv. 3 (2013) 14861494. https://doi.org/10.1039/c2ra22886f.

[41] L.R. Domingo, E. Chamorro, P. Pérez, Understanding the reactivity of captodative ethylenes in polar cycloaddition reactions. A theoretical study, J. Org. Chem. 73 (2008) 4615-4624. https://doi.org/10.1021/jo800572a.

[42] L.R. Domingo, A new C-C bond formation model based on the quantum chemical topology of electron density, RSC Adv. 4 (2014) 32415-32428. https://doi.org/10.1039/c4ra04280h.

[43] A.E. Reed, L.A. Curtiss, F. Weinhold, Intermolecular Interactions from a Natural Bond Orbital, Donor-Acceptor Viewpoint, Chem. Rev. $88 \quad$ (1988) 899-926. https://doi.org/10.1021/cr00088a005. 
[44] A.E. Reed, R.B. Weinstock, F. Weinhold, Natural population analysis, J. Chem. Phys. 83 (1985) 735-746. https://doi.org/10.1063/1.449486.

[45] J.P. Ranck, Modern physical chemistry: A molecular approach, J. Chem. Educ. 78 (2001) 1024. https://doi.org/10.1021/ed078p1024.

[46] L.R. Domingo, F. Ghodsi, M. Ríos-Gutiérrez, A molecular electron density theory study of the synthesis of spirobipyrazolines through the domino reaction of nitrilimines with allenoates, Molecules. 24 (2019). https://doi.org/10.3390/molecules24224159.

[47] L.R. Domingo, M. Ríos-Gutiérrez, P. Pérez, A molecular electron density theory study of the participation of tetrazines in aza-Diels-Alder reactions, RSC Adv. 10 (2020) 1539415405. https://doi.org/10.1039/d0ra01548b.

[48] L.R. Domingo, K. Kula, M. Ríos-Gutiérrez, Unveiling the Reactivity of Cyclic Azomethine Ylides in [3+2] Cycloaddition Reactions within the Molecular Electron Density Theory, European J. Org. Chem. 2020 (2020) 5938-5948. https://doi.org/10.1002/ejoc.202000745.

[49] L.R. Domingo, M. Ríos-Gutiérrez, P. Pérez, Applications of the conceptual density functional theory indices to organic chemistry reactivity, Molecules. 21 (2016). https://doi.org/10.3390/molecules21060748. 